\title{
GETTING FROM HERE TO THERE - MAINSTREAMING WILDLIFE CROSSING STRUCTURES THROUGH TRANSDISCIPLINARY DESIGN APPROACHES TO COLLABORATIVE PLANNING
}

by Arleigh Hack,

B.A. Environment and Urban Sustainability,

Ryerson University, 2016

\author{
A MRP \\ presented to Ryerson University \\ in partial fulfillment of the \\ requirements for the degree of \\ Master in Planning \\ in the Program of \\ Urban Development
}

Toronto, Ontario, Canada, 2018

(C)Arleigh Hack 2018 


\section{AUTHOR'S DECLARATION}

I hereby declare that I am the sole author of this MRP. This is a true copy of the MRP, including any required final revisions.

I authorize Ryerson University to lend this MRP to other institutions or Individuals for the purpose of scholarly research.

I further authorize Ryerson University to reproduce this MRP by photocopying or by other means, in total or in part, at the request of other institutions or individuals for the purpose of scholarly research.

I understand that my MRP may be made digitally available to the public. 


\section{ABSTRACT}

Getting From Here To There - Mainstreaming Wildlife Crossing Structures Through Transdisciplinary Design Approaches To Collaborative Planning

Arleigh Hack

M.Pl. Urban Development, 2018

School of Urban and Regional Planning, Ryerson University

The effectiveness of wildlife crossing structures in mitigating the impacts of roads on species and ecosystems have been well-documented in scientific literature. Despite this, there are challenges associated with translating ecological knowledge into policy and practice. The study examines the planning process for wildlife crossing infrastructure using a case study in the context of the Greater Toronto and Hamilton Area and explored the potential of transdisciplinary collaboration and design thinking to enhance landscape connectivity. The study followed an iterative design research method incorporating knowledge from literature review, policy analysis and subject matter professional expertise derived through participant observation through work with the Toronto and Region Conservation Authority. This supported the development of a conceptual framework for actionable research to encourage the co-creation of practical knowledge and specific planning solutions. In addition, the study contributes valuable insight to the broader literature of sustainable landscape planning, road ecology and transportation planning. 


\section{ACKNOWLEDGEMENTS}

I had the great opportunity to work with two supervisors throughout the duration of this project. To NinaMarie Lister of the Ecological Design Lab at Ryerson University I would like to thank for the reliable guidance and scoping of the project. To Namrata Shrestha of the TRCA, I am grateful for the regular support in developing and framing this project as well as for the exposure to an ecological perspective I would not have otherwise received.

Thank you both for two unique perspectives as well as continually renewing my own motivation and passion I have for this project. Both of your contributions have not only helped create a project I am proud of but also gave me an incredible academic and professional learning experience throughout the process.

The research for this MRP was supported by funding through a Partnership Development Grant of the Social Sciences and Humanities Research Council of Canada (SSHRC) held by Professor Nina-Marie Lister through the Ecological Design Lab at Ryerson University. 


\section{TABLE OF CONTENTS}

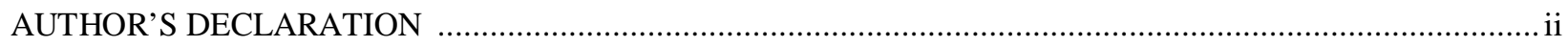

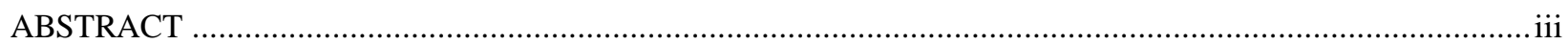

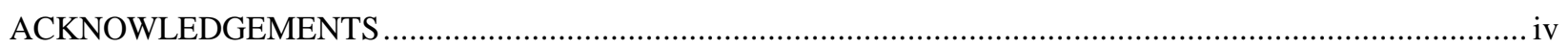

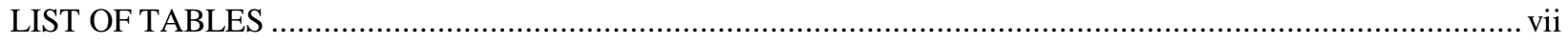

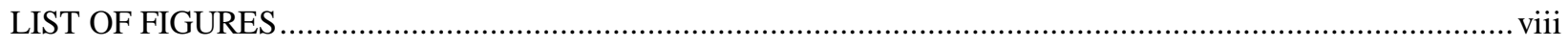

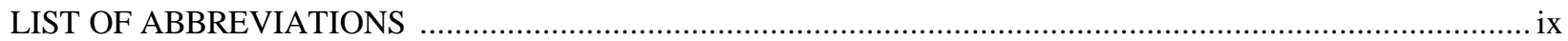

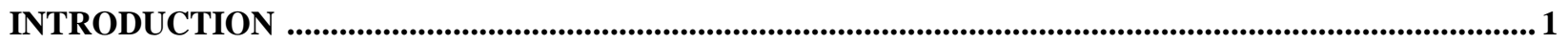

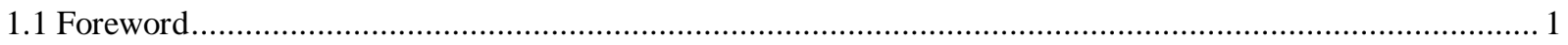

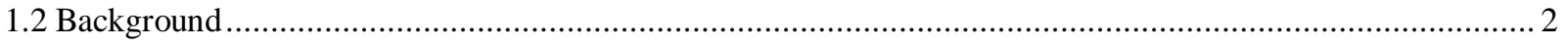

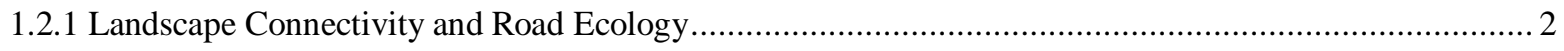

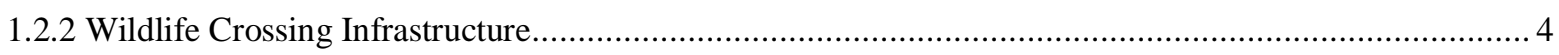

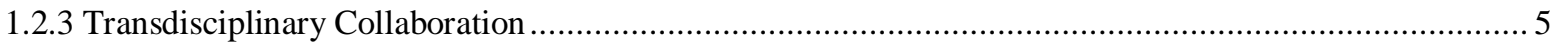

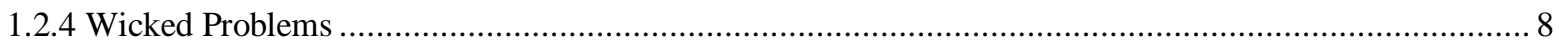

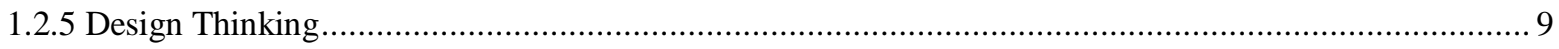

1.2.6 Convergence of Ideas - The CoLaboratory Approach.................................................................... 11

1.2.7 Landscape Connectivity and Wildlife Crossing Planning in the Greater Toronto and Hamilton Area..... 12

PROJECT PURPOSE \& METHODOLOGY …............................................................................................. 16

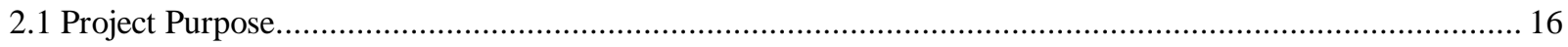

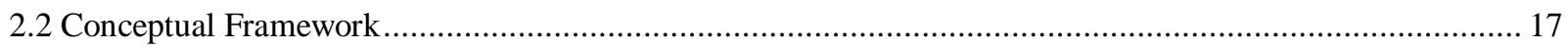

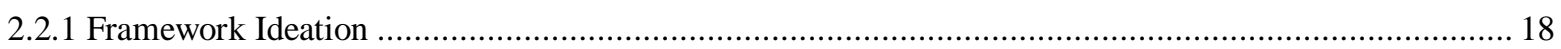

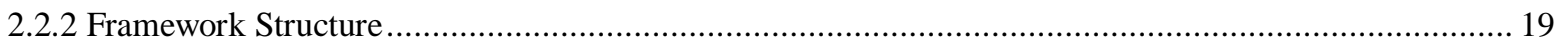

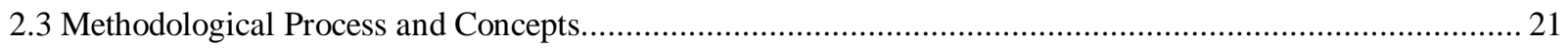

2.3.1 Transdisciplinarity and Participatory Action Research........................................................................ 24

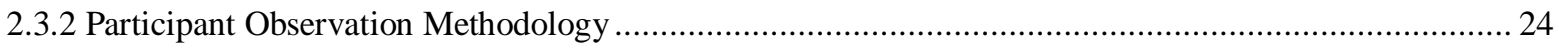

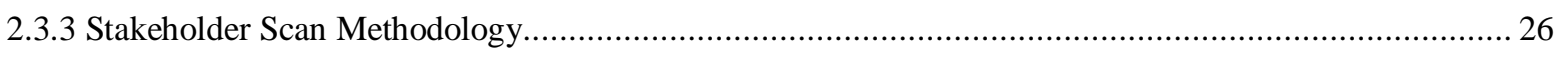

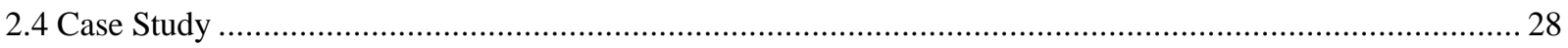

CONCEPTUAL FRAMEWORK IMPLEMENTATION \& ANALYSIS ....................................................... 33

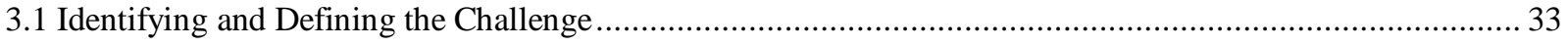

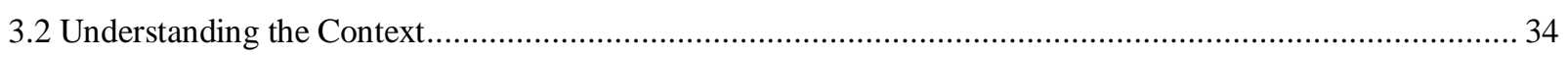

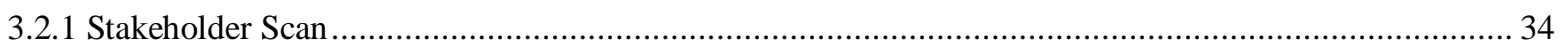

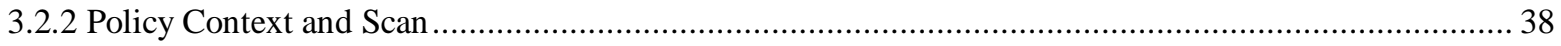

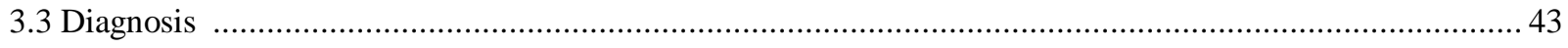

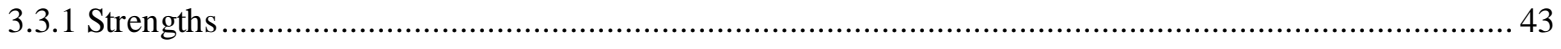

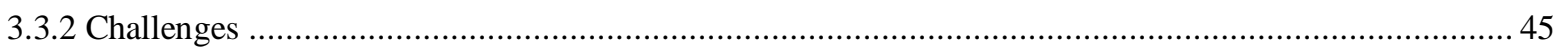




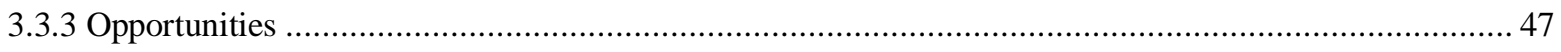

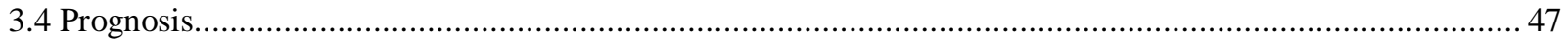

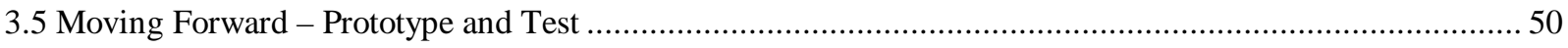

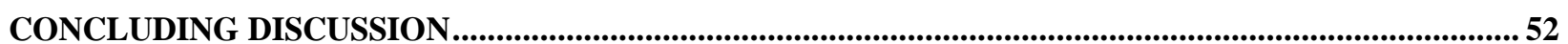

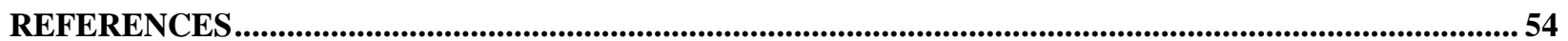




\section{LIST OF TABLES}

Table 1. Wildlife mobility class and preferred crossing structure characteristics (Source: TRCA 2015)

Table 2. Sustainable Landscape Planning Methodology Table (Source: Botequilha Leitão \& Ahern 2002) 


\section{LIST OF FIGURES}

Figure 1. Illustration of three interactions of wildlife with road infrastructure.

Figure 2. Problem and solution space in design thinking (Source: Lindberg, Meinel \& Wagner 2011)

Figure 3. Changes in the Road Network in Southern Ontario from 1935 to 1995 (Adapted from Fenech et al., 2000)

Figure 4. Conceptual Framework.

Figure 5. Six steps of design thinking process (Source: Geissdoerfer, Bocken \& Hultink 2016)

Figure 6. Knowledge generation and sharing process for the study's three key levels of analysis.

Figure 7. Case study context (Adapted from Google Maps 2018)

Figure 8.York Region Official Plan Map 2 illustrating the Regional Greenlands System (Source: York Region 2010)

Figure 9. York Region Official Plan Map 3 illustrating areas of environmental and scientific significance (Source: York Region 2010)

Figure 10. TRCA's preliminary assessment of natural heritage functions reflecting a gradient of priority for crossings (i) high (red) are deep valleys with high priority for habitat and connectivity, (ii) medium (green) are shallow valleys with high existing and potential habitat and connectivity potential, and (iii) low (blue) reflects low priority for habitat and connectivity (Adapted from TRCA 2015).

Figure 11. York Region 2018 10-Year Capital Plan the location of the Major Mackenzie Drive road in the City of Vaughan (Adapted from York Region website)

Figure 12. TRCA data crossing classification for Major Mackenzie Drive. The stream crossings on Humber River and Purpleville Creek are classified as high priority with many species of fauna identified on both sides of the road (Source: TRCA data)

Figure 13. Illustrates the three general stages the land use planning and EA processes. The EA process is the process through with the opportunity for wildlife crossings were captured for Major Mackenzie Drive (Adapted from TRCA 2015).

Figure 14. York Region Official Plan Map 2 excerpt showing the extent of the Regional Greenlands System along Major Mackenzie Drive (Adapted from York Region 2010).

Figure 15. York Region Official Plan Map 3 excerpt showing the extent of ESA and ANSI designated natural areas along Major Mackenzie Drive (Adapted from York Region 2010).

Figure 16. Illustration of CoLaboratory Process and its incorporation into the study framework (Adapted from Aird 2017) 


\section{LIST OF ABBREVIATIONS}

$\mathbf{C A}=$ Conservation Authority

CACE $=$ Crossing and Connectivity Effectiveness Project

$\mathbf{E A}=$ Environmental Assessment

EDL = Ecological Design Lab

GTHA = Greater Toronto-Hamilton Area

MCEA = Municipal Class Environmental Assessment

MOECC $=$ Ministry of Environment and Climate Change

MTO $=$ Ministry of Transportation

PPS $=$ Provincial Policy Statement

$\mathbf{S A R}=$ Species at Risk

TRCA = Toronto and Region Conservation Authority

WVC $=$ Wildlife-Vehicle Collision 


\section{INTRODUCTION}

\subsection{Foreword}

To open this project, a quote from an article published by the School of Forestry and Environmental Studies at Yale University titled "In Defense of Biodiversity” seemed appropriate as it effectively and powerfully alludes to the intent of this study. Author Carl Safina (2018) states:

Extinction wasn't a cost of progress; it was an unnecessary cost of carelessness. Humans could work around the needs of these birds, and these creatures could exist around development. But it took some thinking, some hard work, and some tinkering.

Roads are an inevitable part of growth and development and are necessary to ensure economic and social sustainability for cities and urban regions. However, road networks have significant ecological consequences on the ecosystems they transect. This dichotomy between such an essential infrastructure and its inevitable ecological impacts represents a particularly conspicuous and even pernicious demonstration of the conflict between human society and nature. Transportation networks have always played a significant role in shaping landscapes and are a symbol of economic growth; as such these networks have been provided with a level of both tolerance and ignorance of the ecological consequences they produce (Karlson, Mörtberg, Balfors \& Miljöbedömning och-förvaltning 2014). Although environmental topics in transportation research have received more attention in recent years, this discussion has almost exclusively centered on reducing emissions in response to climate change and the quality of human life, little attention is afforded to the unintended impact of roads to biodiversity and habitat connectivity (Coffin, 2007). This is in spite of wildlife mobility being an essential function to ensure ecosystem resilience to climate change (Lister, Brocki \& Ament 2015) as well as substantial evidence demonstrating that road networks are one of the most destructive contributors to habitat fragmentation (van der Ree, Jeager, van der Drift \& Clevenger 2011). Habitat fragmentation refers to the "patchiness" of a habitat which results in reduced habitat connectivity (De Santo \& Smith 1993). This is a key area of concern within the field of landscape ecology which studies the pattern, processes and interaction of ecosystems within a landscape and how these interactions influence ecological processes (Coffin 2007). 
As will be explored in this paper, considerable research has shown that the impacts of roads on ecosystems and species can be effectively mitigated using wildlife crossing infrastructure. This begs the question of why then are they not more well utilized and how can landscapes be planned more holistically to balance the needs of species and society? If not carelessness, this study has suggested that instead, it is a lack in integrated planning which demands transdisciplinary approaches to collaboration and collective ownership in the creation of solutions to ecological problems.

\section{$\underline{1.2 \text { Background }}$}

\subsubsection{Landscape connectivity and road ecology}

The definition of "landscape connectivity" varies across the literature. For the purpose of this study, the proposed description was adapted from Taylor et al. (1993) to include more explicit reference to the various forms of structures within a landscape. As such, landscape connectivity may be described as the degree to which the landscape and its biotic, abiotic and anthropogenic features facilitates or impedes the movement of organisms between habitat patches (Taylor et al. 1993). Two elements of landscape connectivity are highlighted in this definition: (i) the composition (what is it made of?) and configuration (how are they placed?) of landscape components and (ii) the behaviour of the organisms that move across the landscape (Tischendorf and Fahrig 2000, Moilanen and Nieminen 2002). Coupled with habitat connectivity, it is an essential component of broader ecosystem health and conservation (Beckmann \& Hilty 2010). Landscape connectivity may be influenced by natural features, such as a body of water or mountain range, as well as anthropogenic such as road networks which have been credited by many in the fields of landscape ecology, road ecology and beyond as a core contributor to the global decline in biodiversity (Karlson et al., 2014; van der Ree et al. 2011).

The science of road ecology emerged from this narrative with an aim to understand the unintended ecological implications of roads, in order to contribute knowledge in how to avoid, minimize, and compensate for their negative impacts on individuals, populations, communities, and ecosystems (Van der Ree et al. 2011). Further, the road ecology perspective proposes that engineering is as much related to the impacts of roads on ecosystems as land use planning and transportation policy (Coffin, 2007). This refers to the construction, physical design, utilization and maintenance of transportation infrastructure as a key component in the equation to landscape connectivity (Karlson et al., 2014). 
Roads have short term and long term impacts on species and their ecosystems. Figure 1 illustrates three scenarios of interaction between species and roads. In the short term, Farig and Rytwinski (2009) identified three types of avoidance behaviours that an animal will assume in response to roads and traffic: (i) avoidance of the road surface itself (including when the road design physically prohibits animal movement); (ii) avoidance of the traffic emissions and disturbances such as noise that roads create; and (iii) car avoidance when crossing the road which refers to the ability of the animal to avoid being struck by a vehicle. Alternately, if animals do not exhibit avoidance then they are more likely to cross the road and get into wildlife-vehicle collisions (WVC), thus resulting in road mortality. Either way, roads create barriers to wildlife movement (Forman \& Alexander 1998; Forman et al. 2003) and increased road mortality (Benítez-López et al. 2010; Fahrig \& Rytwinski 2009), both of which have cumulative effects over the long term for species persistence in the landscape.

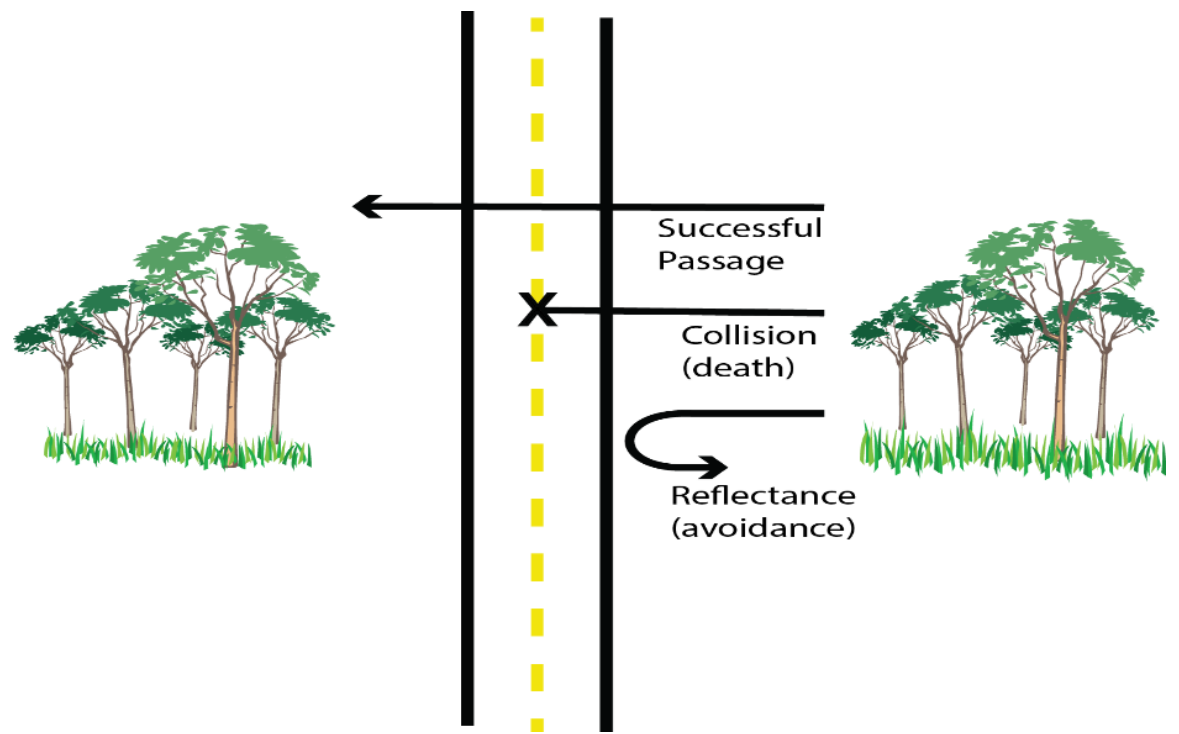

Figure 1. Illustration of three interactions of wildlife with road infrastructure.

The significance of roads to species vary depending on road location and the species characteristics. Some species populations are more vulnerable to impacts of WVCs and increased road mortality than others. For example, amphibians (frogs and toads) and reptiles (snakes and salamanders) have been found to be more vulnerable to WVCs (Huijser et al. 2009; Fahrig \& Rytwinski 2009). This impedes on the ability of species to access areas of habitat needed to feed and breed resulting in genetic isolation (Forman \& Alexander 1998) and even reduced resilience to the effects of climate change and other environmental disturbances (Lister et al. 2015). In addition to behavioural change and direct mortality from WVCs within a species population, broader effects to ecosystems and population genetics are 
apparent as well including metapopulation dynamics, gene flow, range expansion, population persistence, invasion, etc. (Fahrig \& Rytwinski 2009; Sawaya et al. 2013, 2014; Moilanen \& Nieminen 2002; Fagan \& Calabrese 2006).

WVCs have strong implications to human safety and economics as well. Huijser et al (2009) indicated that the cost associated with WVCs with large ungulates are estimated at USD \$8 billion a year in North America alone. In Canada, Transport Canada estimates approximately 4 to 8 WVCs occur every hour with large animals (Lister et al. 2015). Although these cost-related findings are significant, they represent only WVCs with large species. Similar cost-benefit studies for smaller species are non-existent, despite that the frequency of WVCs with smaller species, amphibians and reptiles in particular, are very common and can have a significant impact to the species, ecosystems, as well as people (Huijser et al. 2009; Fahrig \& Rytwinski 2009). This however, alludes to debated arguments surrounding the valuing of nature itself when a monetary value cannot be or is difficult to apply because costing methods consider only effects to humans.

\subsubsection{Wildlife Crossing Infrastructure}

One of the most promising ways to mitigate barrier effects and WVCs is the incorporation of wildlife crossing structures in the design of roads and other transportation networks to provide safe passage for all species. Wildlife crossing structures are diverse in form in order to accommodate different species with different requirements. Table 1 outlines a summary of the structure type and design considerations found to be effective for different types of species ranging from large and highly mobile mammal species to less mobile smaller species such as amphibians and reptiles.

The viability and effectiveness of these structures to provide connectivity, enhance wildlife mobility and reduce WVCs for some species have been supported by a substantial number of road ecology studies over the past years (Lister et al. 2015; Huijser et al. 2009; Van der Ree et al. 2011). However, the implementation of these structures within Ontario generally remain few, ad hoc and opportunistic (Yuan 2014; Elton 2015). The reasons for this vary, but one often cited reason is the large upfront construction costs for crossing structures despite through cost-benefit analysis from Huijser et al. (2009), that indicate these structures offer significant return on investment when the cost of WVCs with large animals are taken into consideration. Further, the retrofitting of roads after the fact to avoid WVCs and improve connectivity is considerably more costly compared to the upfront cost of ecologically considerate design in the first place (Hardy \& Wambach 2015). These and other studies point to the fragmentation between disciplinary and organizational collaboration and the influence of politics as an additional and particularly pernicious barrier (Lister 
et al. 2015; Yuan 2014; van der Ree et al. 2011; Elton 2015). This is due to the intractable nature of decision making and governance systems which conflict with the demands of achieving greater landscape connectivity and sustainability in that it requires a shared sense of responsibility and collective action.

Table 1. Wildlife mobility class and preferred crossing structure characteristics (Source: TRCA 2015)

\begin{tabular}{|c|c|c|c|c|c|c|c|c|}
\hline $\begin{array}{l}\text { Mobility } \\
\text { class }\end{array}$ & Wildlife group & $\begin{array}{l}\text { Preferred } \\
\text { habitat }\end{array}$ & $\begin{array}{l}\text { Maximum } \\
\text { spacing } \\
\text { between } \\
\text { openings }\end{array}$ & $\begin{array}{l}\text { Minimum size of } \\
\text { crossing needed }\end{array}$ & $\begin{array}{l}\text { Preferred } \\
\text { substrate } \\
\text { condition }\end{array}$ & $\begin{array}{l}\text { Preferred } \\
\text { light } \\
\text { condition }\end{array}$ & $\begin{array}{l}\text { Preferred } \\
\text { moisture } \\
\text { condition }\end{array}$ & $\begin{array}{l}\text { Other known preferred } \\
\text { factors affecting the } \\
\text { usage of crossings }\end{array}$ \\
\hline $\begin{array}{l}\text { Restricted } \\
\text { Mobility }\end{array}$ & $\begin{array}{l}\text { Some small } \\
\text { mammals (e.g. } \\
\text { moles) }\end{array}$ & Forests & $25 \mathrm{~m}$ spacing & $\begin{array}{l}\text { Trench drains and } \\
\text { specialized culverts; } \\
\text { smaller than } 0.5 \mathrm{~m}\left(2^{\prime}\right) \\
\text { span but could be } \\
\text { larger structures }\end{array}$ & \begin{tabular}{|l|} 
Natural \\
\end{tabular} & Dark, cover & Dry & $\begin{array}{l}\text { Prefer small structures } \\
\text { with overhead cover, } \\
\text { vegetative cover }\end{array}$ \\
\hline \multirow[t]{2}{*}{$\begin{array}{l}\text { Low } \\
\text { Mobility }\end{array}$} & $\begin{array}{l}\text { Most amphibians } \\
\text { (e.g. frogs, } \\
\text { salamanders) and } \\
\text { reptiles (e.g., snakes) }\end{array}$ & $\begin{array}{l}\text { Forests and } \\
\text { Wetlands }\end{array}$ & $\begin{array}{l}61 \mathrm{~m} \text { spacing, } \\
\max 80-100 \mathrm{~m}\end{array}$ & $\begin{array}{l}\text { Trench drains and } \\
\text { specialized culverts; } \\
\text { smaller than } 0.5 \mathrm{~m}\left(2^{\prime}\right) \\
\text { span but could be } \\
\text { larger structures }\end{array}$ & \begin{tabular}{|l|} 
Natural \\
\end{tabular} & Light & Dry or moist & $\begin{array}{l}\text { Require moisture and } \\
\text { light and should be as } \\
\text { short as possible; drift } \\
\text { fences useful to assist } \\
\text { in passage }\end{array}$ \\
\hline & $\begin{array}{l}\text { Some small } \\
\text { mammals (e.g. } \\
\text { shrews) }\end{array}$ & Forests & $\begin{array}{l}250 m-500 \\
m \text { spacing }\end{array}$ & $\begin{array}{l}\text { Trench drains and } \\
\text { specialized culverts; } \\
\text { smaller than } 0.5 \mathrm{~m}\left(2^{\prime}\right) \\
\text { span but could be } \\
\text { larger structures }\end{array}$ & Natural & Dark, cover & Dry & $\begin{array}{l}\text { Prefer small structures } \\
\text { with overhead cover, } \\
\text { vegetative cover }\end{array}$ \\
\hline \multirow[t]{2}{*}{$\begin{array}{l}\text { Moderate } \\
\text { Mobility }\end{array}$} & $\begin{array}{l}\text { Some medium sized } \\
\text { mammals (e.g. } \\
\text { ermine, weasel, } \\
\text { porcupine, river otter) }\end{array}$ & $\begin{array}{l}\text { Forests and } \\
\text { Riparian }\end{array}$ & $2 \mathrm{~km}$ & $\begin{array}{l}\text { Small underpass; } \\
\text { small box or arch } \\
\text { culverts } 1.5 \mathrm{~m}\left(5^{\prime}\right) \\
\text { span or less }\end{array}$ & Natural & Some light & Dry & $\begin{array}{l}\text { Prefer tall and narrow } \\
\text { structures }\end{array}$ \\
\hline & Reptiles (e.g. turtles) & $\begin{array}{l}\text { Forests and } \\
\text { Wetlands }\end{array}$ & $1 \mathrm{~km}-5 \mathrm{~km}$ & $\begin{array}{l}\text { Small underpass; } \\
\text { small box or arch } \\
\text { culverts } 1.5 \mathrm{~m}\left(5^{\prime}\right) \\
\text { span or less }\end{array}$ & Natural & Some light & Dry or wet & $\begin{array}{l}\text { Prefer small } \\
\text { underpasses, box or } \\
\text { arch culverts, or eco- } \\
\text { passages and should } \\
\text { include minimal rock }\end{array}$ \\
\hline \multirow[t]{2}{*}{$\begin{array}{l}\text { High } \\
\text { Mobility }\end{array}$} & $\begin{array}{l}\text { Some larger } \\
\text { mammals (e.g. black } \\
\text { Bear) }\end{array}$ & Forests & $5 \mathrm{~km}$ & $\begin{array}{l}\text { Medium underpass; } \\
\text { box or arch culverts } \\
\text { larger than } 1.5 \mathrm{~m}\left(5^{\prime}\right) \\
\text { span to } 2.4 \mathrm{~m}\left(8^{\prime}\right) \text { span }\end{array}$ & Natural & & $\begin{array}{l}\text { Dry, } 1 \mathrm{~m} \\
\text { high, wide }\end{array}$ & $\begin{array}{l}\text { Prefer constricted } \\
\text { passageways with } \\
\text { vegetative cover }\end{array}$ \\
\hline & $\begin{array}{l}\text { Some medium sized } \\
\text { mammals (e.g. fisher) }\end{array}$ & Forests & $15 \mathrm{~km}$ & $\begin{array}{l}\text { Medium underpass; } \\
\text { box or arch culverts } \\
\text { larger than } 1.5 \mathrm{~m}\left(5^{\prime}\right) \\
\text { span to } 2.4 \mathrm{~m}\left(8^{\prime}\right) \text { span }\end{array}$ & Natural & Some light & Dry & $\begin{array}{l}\text { Prefer tall and narrow } \\
\text { structures }\end{array}$ \\
\hline
\end{tabular}

\subsubsection{Transdisciplinary Collaboration}

A common thread linking the challenge of planning for landscape connectivity and wildlife mobility across the broad spectrum of literature discussed in the previous section is the identification of an action gap between strongly supported ecological evidence and fields of practice (Wang, Tan, Zhang \& Nassauer, 2014; Opdam, Foppen \& Vos, 2001; Nassauer \& Opdam, 2008; Tress et al. 2005; Austin, Slesar \& Hammond 2010; Holling \& Goldberg 1971/2014; Musacchio, 2011; Dramstad \& Fjellstad, 2011; Ahern, 2013/2012; Niemelä, 1999; Lister et al., 2015). In response to this challenge, a call for more integrative, action-oriented and localized research is evident (Wang et al., 2014; Wu et al. 2017). Wang et al. (2014) identified the fields of planning, design, engineering and governance as fields of practice critical for the application of landscape ecological knowledge. Many studies spanning decades of research support the integration of and collaboration between the fields of ecology and planning (Niemelä 1999; Holling \& Goldberg 1971/2014; Ahern 2012) as well as the fields of transportation planning and engineering in contributing to improved 
landscape connectivity and conservation (Yuan 2014; Coffin 2007; Kociolek et al. 2014). This notion is well described in Lister et al (2015) in that the problem of habitat fragmentation and WVCs is not in the purview of any single agency, rather, the problem itself and the required solutions touch on a wide range of disciplines and agencies. This resonates with the characteristics of what has been referred to as a messy, complex and wicked problem.

Transdisciplinarity entails the collaboration between stakeholders of two or more disciplines with a high level of integration between varied disciplinary sets of knowledge in solving a common problem through collaborative research or decision making process (Leavy 2011). Perspectives on transdisciplinarity vary in the literature, but many researchers consider it a research method, research outcome, an approach to the research process as well as a novel and integrated way of thinking across disciplines (Leavy 2011). Particularly relevant in addressing the identified action gap, is the consideration of transdisciplinarity as a bridge between academia and the world of practice in order to address real-world problems which can only be solved through a holistic form of collaboration without compartmentalization into narrow disciplinary perspectives (Leavy 2011; Godeman 2008). This emphasizes that collaboration between academia and stakeholders operating within fields of practice is necessary. In the context of landscape connectivity these stakeholders external to academia would including scientists, planners, engineers and policy makers (Wang et al. 2014). Public participation in transdisciplinary approaches within landscape planning are also considered essential and even as significant as the perspectives of experts (Wang et al. 2014; Wu et al. 2017). Van der Ree et al. (2001) extends this logic to road ecology and wildlife crossing planning, emphasizing that awareness and engagement of the public is essential to influence meaningful participation of decision makers of local, regional and even national governments. This implies that transdisciplinary approaches are essential to the goals of achieving connectivity and sustainability across landscapes.

Transdisciplinary research embodies and supports the objectives of action research in producing "actionable knowledge" and practical solutions to real-world problems, therefore narrowing the gap between science and practice (Wang et al. 2014; Nassauer \& Opdam, 2008). The potential for action research lies in its ability to leverage the lessons from practice in the setting of academic research. Wang et al. (2014) position two reasons why this approach is particularly effective in addressing the action gap: i) practice is action, in that it provides insight into the intent of decision makers and introduces ecological findings in a functional way, and ii) practice is local, which suggests that local landscapes are familiar to all stakeholders and contributing to more informed decision making and tangible 
solutions. Leavy (2011) outlines key principles that characterize transdisciplinarity research. Of particular relevance to addressing the action gap is the problem-centered nature of the approach which determines the methodology and use of disciplinary knowledge, which can result in the emergence of innovative and practical solutions and methodological frameworks. In addition, an emphasis on holistic and iterative research processes demands flexibility and openness to new and diverse insights with the ultimate objective to continually enhance the research outcomes.

Transdisciplinary collaboration is, unsurprisingly, difficult and usually unfolds with setbacks and challenges. As much as it can be a way to approach complex problems, it is in itself complex. This largely has to do with the rigidity of the institutional frameworks previously discussed, as well as the fundamentally different epistemological foundations upon which other disciplines, such as transportation planning and engineering, are based. Working in transdisciplinary settings has been identified as one of the most significant challenges facing landscape ecology as well as environmental and sustainability planning and policy (Wu \& Hobbs 2002; Dale \& Hill 2001). Key components behind this challenge include: i) a lack in common understanding in ecological concepts (Tress et al. 2005), this is further reflected in the work of Yuan (2014) regarding wildlife crossing implementation in the City of Toronto, ii) jurisdictional and cross boundary concerns as well as competing perspectives of landscape management (Petersen, Montambault \& Koopman 2014; Nassauer \& Opdam, 2008), and iii) communication of scientific knowledge and concepts to diverse audiences (Tress et al. 2005; Dramstad \& Fjellstad 2011; Luz 2000).

Godeman (2008) identifies a list of key challenges resulting from the complexity of transdisciplinary collaboration, that of "achieving understanding" and "common knowledge base" are relevant in the planning for landscape connectivity and crossing structures. Similar to the identified lack of understanding of ecological concepts by Tress et al. (2005), when considering the range of stakeholders involved, including engineers, ecologists, planners and other municipal staff and decision makers, the same is true of common understanding of important concepts and processes between all these stakeholders. In the operationalization of holistic landscape planning, dialogue is required to exchange specialist knowledge between those involved in a way that adequately communicates what is meant to what is actually understood by members of different disciplines. The importance of communication between various stakeholders extends to the fields of planning and engineering as well. The field of planning is no stranger to the importance of communication in collaborative planning. Consider Haberman's theory of communicative action (1984) which highlights the role of language in building common understanding for consensus on a course of action or strategy or the importance of collaborative planning in the planning profession studied by Healey (1997). Yuan (2014) 
reflects that transportation engineering processes are not as transparent and accessible to outside stakeholders, in addition, limited opportunity exists in the Greater Toronto and Hamilton Area (GTHA) for the communication of road ecology concepts to transportation departments. A "common knowledge base”, or a shared frame of reference, is important to ensure that all participants are well informed about the subject matter but also who has what knowledge and which knowledge is important in which aspects of the problem solving equation (Godeman 2008). These two challenges are apparent in planning for wildlife crossings in the GTHA. A general lack in understanding of the process and the interrelationship between important actors as well as a lack in common knowledge base regarding key concepts and goals of road ecology contribute to the difficulty in transdisciplinary collaboration.

\subsubsection{Wicked Problems}

Much of the most pressing and complex environmental challenges seen today can be characterized as wicked problems. Problems of landscape connectivity such as habitat fragmentation and biodiversity loss fall within this “wicked” classification as they represent complex socio-ecological challenges (Westley \& McGowan 2014; Xiang 2013). Rittel and Webber (1973) first developed a group of qualities characterizing wicked problems that are well summarized by Westley and McGowan (2014): they have no definite answer, there are no right or wrong solutions only better or worse ones, they may only be evaluated through a trial and error bases, and are typically systematic of broader "higher-level" problems. Environmental problems, including landscape connectivity, align with these qualities as they inherently transcend jurisdictional divides and are "high-level" problems rooted in local conditions. This suggests that any solution will not be universally applicable or appropriate to any context, nor will these solutions be straightforward. This positions these environmental challenges as a promising candidate for transdisciplinary collaboration.

The science of wildlife crossing infrastructure, although an emerging field without a clear standard praxis, is largely a process of trial and error itself as the continued study of existing and new structures informs the design and application of future structures. Lister et al. (2015) identifies this quality as adaptive design and emphasizes this as integral in the future of wildlife crossing and landscape connectivity research, and is a framework which should be supported in order to facilitate the advancement of the science and practice. These concepts of adaptive design, crossjurisdiction and cross-disciplinary planning and decision making, deemed necessary for confronting wicked problems, 
are incompatible with existing governance and institutional decision making structures which are characteristically rigid and intractable.

The science of addressing complex and wicked problems point to the need for transdisciplinary collaboration (Ahern 2012; Godemann, 2008), transdisciplinary research (Godemann, 2008) as well as the design thinking process (Westley \& McGowan 2014; Nassauer \& Opdam 2008; Musacchio 2011; Ahern 2012). Similarly, a considerable number of studies call for a need for transdisciplinary approaches to planning and research in narrowing the gap between science and practice in the broader field of landscape ecology and planning (Wang et al. 2014; Tress et al. 2005; Nassauer \& Opdam, 2008) as well as specifically in the planning and implementation of wildlife crossings (Lister et al. 2015; Kociolek et al. 2014; Austin et al. 2010).

\subsubsection{Design thinking}

Design thinking is a well-recognized approach to developing physical products and processes and is now well utilized across many fields including business, policy formulation, product design, engineering and beyond (Westley \& McGowan 2014). Design has historically been contained to fields who use the design process to produce physical objects such as new products, technologies and infrastructure (Westley \& McGowan 2014). However, it is increasingly used in the design process to find innovative solutions to non-technical issues within decision making, policy formulation and the planning process (Westley \& McGowan 2014).

The descriptions of design thinking across the literature tend to highlight different aspects of its process and objectives. Lindberg, Meinel and Wagner (2011) identify three core characteristics of design thinking which is illustrated in Figure 2. These include the exploration of the problem space, exploration of the "solution space" and the iteration between these two spaces. This is a valuable perspective as it demonstrates a central focus of design thinking towards real-world problems and the generation of solutions. 


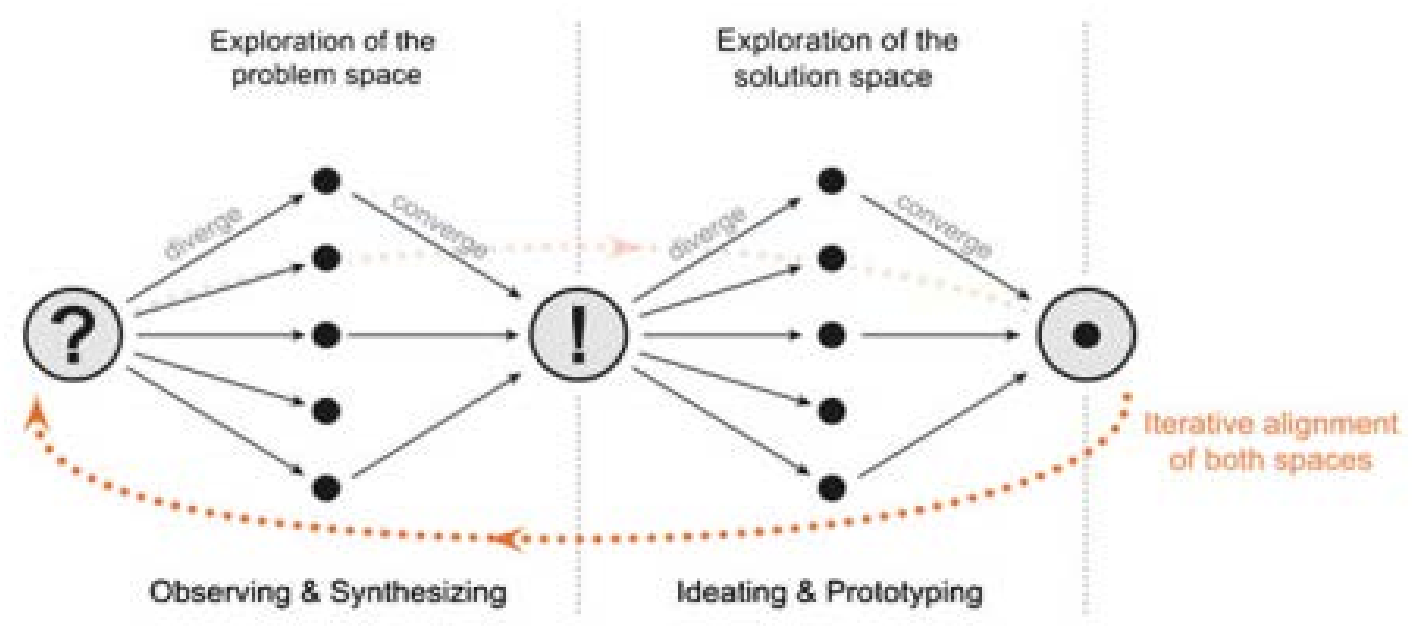

Fig. 1 Problem and solution space in design thinking

Figure 2. Problem and solution space in design thinking (Source: Lindberg, Meinel \& Wagner 2011)

In addition, the design thinking process is highly iterative, meaning it requires constant shifting between the “problem space” and "solution space” to accommodate new knowledge and continually improve upon the final product (Cross 1982). These qualities are strikingly familiar to the characteristics and requirements of transdisciplinarity, although transdisciplinarity usually emphasizes process design as outcomes and design thinking typically on product deliverables as outcomes. Geissdoerfer, Bocken and Hultink (2016) and Waloszek (2012) identified five characteristics of design thinking:

1. A human centred approach;

2. Strong integration of experimenting with artefacts;

3. Collaboration with multidisciplinary teams;

4. An integrative view on complex problems; and,

5. A typical six step process (which will be discussed in a later, see Figure 5).

Other researchers of design thinking support these characteristics. A human centered approach is highly considerate of context (Cross 1982). Experimentation with artefacts, if taken from the perspective of design for nontechnical process solutions whereby an artifact is not just physical but different forms of knowledge as well, suggests that design thinking is a generative process that combines existing knowledge to produce innovative solutions (Razzouk \& Shute 2012). Its use of multidisciplinary collaboration positions it as an ideal framework in which to 
apply transdisciplinary action research, an application that is well recognized (Thering \& Chanse 2011). An integrative view on complex problems lends to its holistic nature and its compatibility with addressing wicked problems (Cross 1982). The design process has been considered a useful avenue for addressing wicked problems due to its comparatively chaotic, cyclic and iterative characteristics as well as its problem-solution orientation (Cross 1982; Westley \& McGowan 2014). The design process has been hailed as having significant potential for facilitating transdisciplinary collaboration and providing the grounds for necessary shared understanding in the context of solving wicked landscape problems (Westley \& McGowan 2014; Nassauer \& Opdam 2008; Musacchio 2011). Musacchio (2011) agrees that the design process is particularly promising in landscape ecology and planning, however that it is largely underutilized in these fields.

Design as a research method follows a parallel logic to design thinking in product creation. Knowledge production in a design research context is abductive and typically syncretic in which it inherently draws upon and converges various schools of thought and practice to uncover the most likely explanation for or solution to a complex, unclear, or poorly understood problem or research question (Swaffield \& Deming 2011). Swaffield and Deming (2011) describe the design research method as reflexive in that is shifts between theoretical and empirical evidence. The nature of design research has traction in supporting transdisciplinary collaboration and action research as well as in its application to landscape research and addressing the gap between science and practice.

\subsubsection{Convergence of Ideas- The CoLaboratory Approach}

The above discussion on transdisciplinarity, wicked problems and design thinking have highlighted the similarities and interconnectedness of these streams of thought and practice and its theoretical and real application in the context of landscape connectivity and wildlife crossing infrastructure. The CoLaboratory approach proposed in this paper is intended to develop a specific strategy for integrative planning (as advocated by Lister, Brocki \& Ament 2015 in the context of wildlife mitigation). As such, it converges these topics within a shared arena whereby the coproduction of knowledge between a transdisciplinary set of collaborators occurs through a design thinking process to develop solutions to complex problems. Precedents for the CoLaboratory approach can be found within dialogue on design thinking, transdisciplinary collaboration and knowledge co-production (Aird 2017; Carruthers \& Lister 2011; Lister, Brocki \& Ament 2015). Further, the use of the CoLaboratory in solving landscape scale challenges is well supported (Tress et al. 2005; Opdam \& Nassauer 2008). 
An example of the CoLaboratory approach within the context of landscape connectivity is the International Wildlife Crossing Infrastructure Design Competition organized by a multi-stakeholder partnership between academia and governmental agencies in 2010. Transdisciplinary teams comprising landscape architects, engineers, biologists, and more engaged in a design process to produce innovative infrastructure solutions for wildlife crossing infrastructure for North American roadways (ARC Solutions 2014). The resulting designs have sparked awareness and engagement with and between diverse disciplines. However, as previously mentioned, design process is still relatively new in the development of design solutions to non-technical problems. The ARC competition represents the potential of the CoLaboratory approach and design thinking process for wildlife crossings primarily for structural, physical solutions.

This example demonstrates that the power of this exercise is the bringing together of these diverse practitioners to collaboratively develop effective solutions outside of the traditional institutionally, legislatively and jurisdictionally fragmented context in which this design process would normally operate. This suggests that regardless of the nature of the intended output, a physical artefact or not, the process to reaching that output is effective and promising. It is clear that precedents of such an exercise utilizing the lessons of transdisciplinarity and design thinking in addressing process-related barriers to wildlife crossing infrastructure are as of yet a novel area of inquiry.

\subsubsection{Landscape Connectivity and Wildlife Crossing Planning in the Greater Toronto and Hamilton Area}

The GTHA is a region within southern Ontario including the City of Toronto, the City of Hamilton and Regional Municipalities of York, Durham, Halton and Peel. The GTHA is currently home to over six million people (Metrolinx 2008). In the Ontario Ministry of Finance population growth projections to 2041 (2017), the Greater Toronto Area is expected to be the fastest growing region in the province, with its population increasing by about 42.3\% to reach 9.6 million by 2041, accounting for 52.7\% of Ontario's total population (MFO 2017). Growth rate is expected to be significantly greater in suburban Greater Toronto Area census divisions surrounding the City of Toronto adding 1.8 million people to these areas by 2041 (MFO 2017). This study excludes the City of Hamilton which is anticipated to achieve similar growth rates to the other suburban regions and contribute to the anticipated population of 8.6 million people across the entirety of the GTHA by 2031 (Metrolinx 2008). Road density in Ontario has long been increasing, with the total length of roads increasing from 7,133 $\mathrm{km}$ to 35,637km in the past 60 years (OREG 2010), and can be expected to continue to support the projected growth to 2041 further exacerbating pressure on 
wildlife populations. Figure 3 illustrates the extent of road density within southern Ontario. This expansion of the road network positions the GTHA as a significant region for growth as well as threat to local ecosystems and wildlife.

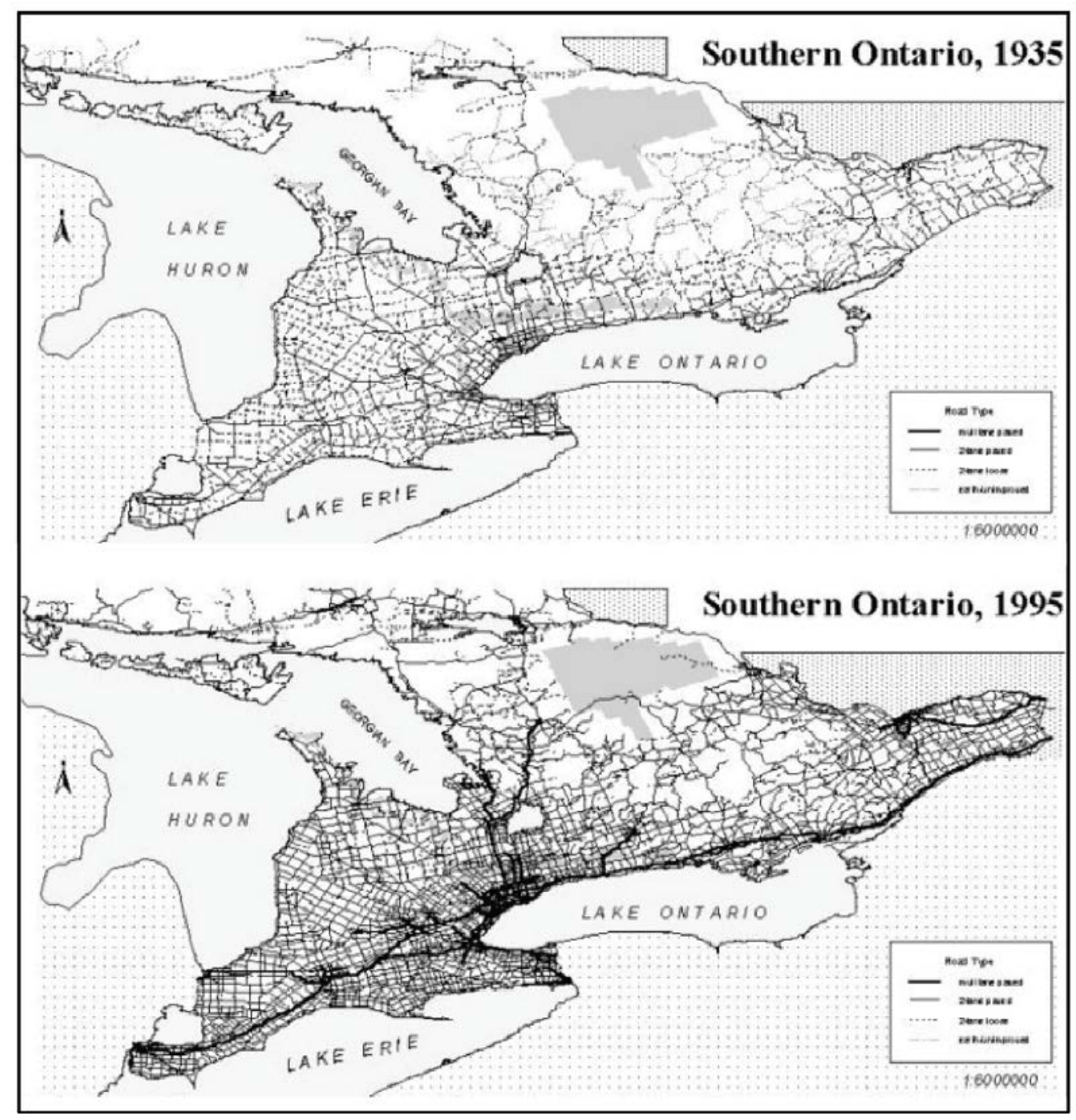

Figure 3. Changes in the Road Network in Southern Ontario from 1935 to 1995 (Adapted from Fenech et al., 2000)

While the southern regions of Canada represent the most populated and urbanized regions in the country, the same is true for the Canada's biodiversity richness and abundance, which is most substantial in these southern, temperate regions (MNR 2008). This dichotomy is particularly potent in southern Ontario, the most populated and urbanized region in Canada, but also among the most biodiverse regions across the country and North America (OBC 2011; MNR 2008). The suburban areas along the periphery of the GTHA also contain extensive areas of land within the Greenbelt Plan (2017), Oak Ridges Moraine Conservation Plan (2017) and Niagara Escarpment Plan (2017) which are protected through provincial policy for their natural heritage features and ecological function. These 
provincial policies strictly govern land use within these areas and are a critical governing structure in the environmental conservation and preservation within the GTHA and all of southern Ontario. In addition southern Ontario is located within the Mixedwood Plains Ecozone which includes the Carolinian life zone which extends within the GTHA particularly in Hamilton to Toronto regions which is considered the most endangered ecosystem in Canada and home to some of the country's most endangered species and globally significant habitats (OBC 2011; Cowie 2011).

Habitat loss and fragmentation represents a core threat to $97 \%$ of all species at risk (SAR) in southern Ontario including within protected areas of the provincial plans and the threats are growing due to population growth, increased densification and farmland pressures (Cowie 2011; MNR 2008). In particular, wildlife road mortality has been listed as a significant threat to SAR, in Ontario government agencies have indicated WVCs as a key threat to 18 reptile species, 3 amphibian species, 10 bird species, and 1 insect species within this category (Vanlaar, Gunson, Brown \& Robertson 2012). The Ontario Ministry of Transportation (MTO) 2005 statistics indicated about 14,000 WVCs occur per year in Ontario alone, an unpublished study by MTO estimated this translates to a true cost of $\$ 1.1$ billion (Vanlaar et al. 2012). Similar to previous discussion, this data is limited to collisions with large ungulates and typically on provincial roadways, leaving a large gap in understanding of the prevalence and impacts of WVCs on local roads.

Mitigation solutions to WVCs in southern Ontario, wildlife crossing structures in particular, are typically based on conservation-related considerations and are geared towards SAR target species of reptiles and amphibians identified in the Endangered Species Act (2007) (Vanlaar et al. 2012). This contrasts to other regions such as Northern Ontario, British Columbia or Newfoundland and Labrador which base their mitigation solutions on socio-economic as well as conservation-related considerations of larger animals as they represent a more significant threat. Despite decades of considerable evidence of the impact of roads on wildlife and entire ecosystems, the importance of habitat connectivity and the effectiveness of wildlife crossings, in southern Ontario, landscape connectivity remains a great concern and physical mitigation infrastructure remain an ad hoc, opportunistic and largely underused (Yuan 2014; Lister et al. 2015). The implementation of wildlife crossings in the region is mostly dependent on road construction or maintenance projects emerging from municipal transportation plans. Opportunities to commence the planning process are captured either through the environmental assessment process (EA) or the land use planning process. Intervention and collaboration in the early stages of these processes are critical in ensuring most desirable outcomes. However, the process confronts multiple obstacles including timing misalignments between ecological data collection and planning and decision making processes, lack in process clarity, and barriers to meaningful communication, knowledge sharing 
and collaboration across jurisdictional divides. These challenges result in the complication of wildlife crossing implementation, may influence the preferred structure design for wildlife movement, and even result in missed opportunities all together. Lister et al. (2015) points to the need for more local precedents of crossing structures being implemented, which are currently relatively uncommon, in order to encourage routine uptake as mitigative tool.

Given the ecological significance and the ever increasing burden of urbanization and growth within southern Ontario, the GTHA is positioned as a significantly important region, provincially and nationally, to study and accelerate the implementation of innovative and holistic solutions to address landscape connectivity. As the continued development of linear transportation infrastructure will maintain on course in the coming years, the importance of mainstreamed mitigation techniques that facilitate wildlife mobility across transportation networks is imperative. 


\section{PROJECT PURPOSE \& METHODOLOGY}

\subsection{Project Purpose}

This study converges the various concepts explored in the previous section. The purpose of the study is to examine the planning process for wildlife crossing infrastructure in the context of the GTHA and envision the potential of transdisciplinary collaboration and design thinking to enhance landscape connectivity within this context. The study has a number of objectives:

- $\quad$ to develop a framework for actionable research to encourage a more collaborative, effective and streamlined approach to the planning and implementation of wildlife crossings as well as landscape connectivity in a more general sense;

- $\quad$ to provide an example of transdisciplinary participant action research and design thinking to the research and practice of landscape connectivity and road ecology; and,

- $\quad$ to provide a context-sensitive lens within the GTHA through a project-specific case study in York Region.

This project is part of a larger SSHRC-funded partnership research grant investigating landscape connectivity; as such, it was conceived and developed collaboratively between two of the partner organizations: the TRCA road ecology team and the Ecological Design Lab (EDL) at Ryerson University, and myself (the author). This project will draw therefore on expertise and data from my work at both organizations. The project supports the federally funded work of the EDL which seeks to advance integrative planning approaches to landscape connectivity. The project will inform the regional work of the TRCA to support the transportation planning through EA and land use planning process. This project will facilitate the TRCA's ongoing implementation of the Crossing Guideline for Valley and Stream Corridors (TRCA 2015) and conducting the Crossing and Connectivity Effectiveness Study (CACE) project. Furthermore, this study is part of the broader research collaboration between academic research and practitioners such as the TRCA. The results of this study are expected to support and contribute to future research undertaken by the EDL and in collaboration with the TRCA. To illustrate this relationship as well as clarify the structure and process of the study for potential future replication and adaptation, a conceptual framework has been developed and applied. 


\subsection{Conceptual Framework}

Figure 4 illustrates the conceptual framework which was developed to guide actionable research regarding wildlife crossing structures. This framework is intended to be applied to projects ranging from the project scale to landscape/regional scale and will encourage a more collaborative approach to the research and implementation of crossing structures. It will do this through providing a proof of concept in the integration of design and transdisciplinary approaches in this context within a case study in the GTHA. In addition, it will provide structure to the analysis this study as well as a visual roadmap for how this research is proposed to be incorporated into and inform the future research of the EDL and TRCA.

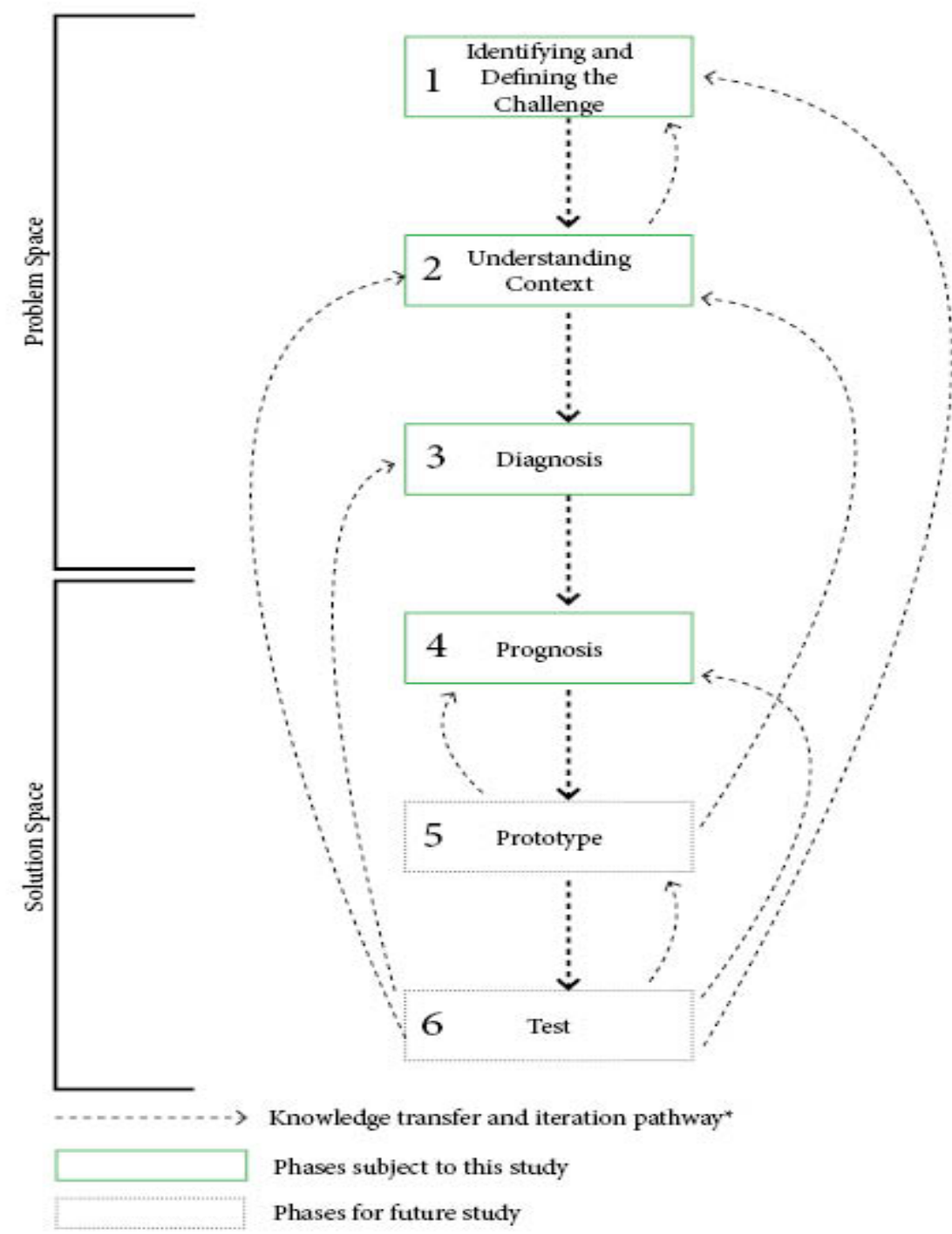

Figure 4. Conceptual Framework.

* Knowledge transfer and iteration pathway to be generated through collaborative approaches to knowledge generation. For this study, the collaborative approach used is outlined in section 2.2 and illustrated in Figure 6 


\subsubsection{Framework Ideation}

The conceptual framework is adapted from various relevant and tested frameworks involving sustainable landscape planning and the design thinking process. These different approaches were chosen due to their considerable contribution to the field of planning, environmental management, innovative process design and their compatibility with the characteristics and requirements of transdisciplinarity. The goal of this research is not to duplicate efforts by developing a unique planning framework, but build upon this existing wealth of knowledge and expertise and adapt it to a more localized, context specific area of inquiry. This is important as it has been demonstrated that although transdisciplinary processes can and do work in supporting adaptive planning for ecosystem problems, there are challenges with exporting these tested frameworks to different contexts (Ahern et al. 2014).

The work of Botequilha Leitão and Ahern (2002) has informed the development of the methodological framework for this study. Botequilha Leitão and Ahern (2002) analyzed a number of ecological-based physical planning methodologies (see Table 2) in order to synthesize their key characteristics into a unified sustainable landscapes planning framework. The idea here is that there are so many disjointed processes for ecosystem management among various disciplines and practitioners that the planning for sustainable landscapes becomes inconsistent and more complicated. The researchers suggest that a unified framework in which all practitioners would operate for this shared goal would help enhance effectiveness. They summarize the key phases on the process of sustainable landscape planning into 5 phases: 1) Focus, 2) Analysis and public participation, 3) Diagnosis, 4) Prognosis, meaning the development and evaluation of alternative solutions and recommendations, and 5) Synthesis, which involves the implementation and monitoring of the proposed solutions and recommendations (Botequilha Leitão \& Ahern 2002). As planning for wildlife crossing infrastructure to address habitat fragmentation could be considered a beneficiary of this sustainable landscape planning framework, it has been used as the foundation for the proposed framework for the study.

The nature of this study as transdisciplinary action research supports the incorporation of a design thinking lens. As discussed in the previous section, design thinking characteristics point to a need for multidisciplinary teams, the exploration of the "problem space" and the "solution space" as well as continuous iteration between these spaces. Figure 5 illustrates the characteristic six steps in the design thinking process. These steps were also adapted 
into the steps of the sustainable landscape planning model with emphasis on the design process focus on the dissection of the "problem space" and "solution space" into steps and iteration between them.

Table 2. Sustainable Landscape Planning Methodology Table (Source: Botequilha Leitão \& Ahern 2002)

Table 1

Comparison of planning phases or stages in several ecological-based physical planning methodologies

\begin{tabular}{|c|c|c|c|c|c|c|c|c|}
\hline \multicolumn{9}{|l|}{ Planning phases } \\
\hline \multicolumn{2}{|l|}{ Landscape planning } & \multicolumn{2}{|l|}{ Landscape ecology } & \multirow{2}{*}{$\begin{array}{l}\text { EIA } \\
\text { Morgan, 1998; } \\
\text { Treweek, } 1999\end{array}$} & \multirow{2}{*}{$\begin{array}{l}\text { Ecosystem } \\
\text { management } \\
\text { McGarigal, 1998a }\end{array}$} & \multirow{2}{*}{$\begin{array}{l}\text { Rural planning } \\
\text { Golley and } \\
\text { Bellot, } 1999\end{array}$} & \multirow{2}{*}{$\begin{array}{l}\text { Landscape } \\
\text { ecological planning } \\
\text { Ahern, } 1999\end{array}$} & \multirow{2}{*}{$\begin{array}{l}\text { Sustainable land } \\
\text { planning (our proposal }\end{array}$} \\
\hline Fabos, 1985 & Steinitz, 1990 & Forman, 1995 & Zonneveld, 1995 & & & & & \\
\hline $\begin{array}{l}\text { Identification of } \\
\text { issues/needs }\end{array}$ & $\begin{array}{l}\text { Representation: } \\
\text { how to describe } \\
\text { the landscape? }\end{array}$ & $\begin{array}{l}\text { Structural and } \\
\text { functional analysis }\end{array}$ & $\begin{array}{l}\text { Initial consultations: } \\
\text { objectives, data, etc. }\end{array}$ & Scoping & Definition of goals & $\begin{array}{l}\text { Setting goals and } \\
\text { objectives }\end{array}$ & Goals & Focus \\
\hline $\begin{array}{l}\text { Assessment of } \\
\text { environmental } \\
\text { and socio-economic } \\
\text { resources }\end{array}$ & $\begin{array}{l}\text { Process: bow does } \\
\text { the landscape work? }\end{array}$ & $\begin{array}{l}\text { Establishing } \\
\text { relationships } \\
\text { between structure } \\
\text { and functioa }\end{array}$ & $\begin{array}{l}\text { Surveys: (a) land } \\
\text { use requirements } \\
\text { and limitations, } \\
\text { (b) land qualities }\end{array}$ & $\begin{array}{l}\text { Description of the } \\
\text { study area: } \\
\text { environmental, socio- } \\
\text { ecoaomic, cultural }\end{array}$ & $\begin{array}{l}\text { Caracterization of } \\
\text { the study area: } \\
\text { environmental, } \\
\text { socio-economic } \\
\text { and cultural }\end{array}$ & $\begin{array}{l}\text { Inventory phase, } \\
\text { public participation }\end{array}$ & $\begin{array}{l}\text { Assessment of ABC } \\
\text { resources, public } \\
\text { participation }\end{array}$ & $\begin{array}{l}\text { Analysis, public } \\
\text { participation, } \\
\text { e.g. SWoT }\end{array}$ \\
\hline Goals and objectives & $\begin{array}{l}\text { Evaluation: is the } \\
\text { current landscape } \\
\text { functioning well? }\end{array}$ & $\begin{array}{l}\text { Evaluation based } \\
\text { on two attributes: } \\
\text { (a) rarity and } \\
\text { (b) recovery }\end{array}$ & $\begin{array}{l}\text { Land suitability } \\
\text { studies comparison, } \\
\text { matching of } \\
\text { (a) and (b), socio- } \\
\text { economic analyses, } \\
\text { EIA considerations }\end{array}$ & $\begin{array}{l}\text { Identification and } \\
\text { descriptivon of } \\
\text { environment, impacts }\end{array}$ & $\begin{array}{l}\text { Needs assessment: } \\
\text { identifying the issues }\end{array}$ & $\begin{array}{l}\text { Diagnosis of the } \\
\text { problem }\end{array}$ & $\begin{array}{l}\text { Identification of } \\
\text { spatial conflicts and } \\
\text { design of spatial } \\
\text { concepts }\end{array}$ & Diagnosis \\
\hline $\begin{array}{l}\text { Development of } \\
\text { alternative plans }\end{array}$ & $\begin{array}{l}\text { Change: how the } \\
\text { landscape might } \\
\text { be altered? } \\
\text { Scenarios }\end{array}$ & $\begin{array}{l}\text { Synthesis: setting } \\
\text { land protection } \\
\text { prioritics }\end{array}$ & $\begin{array}{l}\text { Presentation of results, } \\
\text { discussion of } \\
\text { management scenarios }\end{array}$ & $\begin{array}{l}\text { Prediction of } \\
\text { environmental } \\
\text { impacts (sometimes } \\
\text { includes development } \\
\text { of alternatives and } \\
\text { its evaluation }\end{array}$ & $\begin{array}{l}\text { Finding solutions } \\
\text { alternative plans and } \\
\text { its evaluation }\end{array}$ & $\begin{array}{l}\text { Alternative solutions, } \\
\text { its evaluation and } \\
\text { contrast, and } \\
\text { cost-benefit analysis }\end{array}$ & $\begin{array}{l}\text { Definition of } \\
\text { planning strategies }\end{array}$ & $\begin{array}{l}\text { Prognosis: alternative } \\
\text { plans and evaluation, } \\
\text { public participation, } \\
\text { e.g. SWOT }\end{array}$ \\
\hline \multirow[t]{3}{*}{$\begin{array}{l}\text { Selection of an } \\
\text { alternative }\end{array}$} & $\begin{array}{l}\text { Impact: what } \\
\text { differences might } \\
\text { changes cause? } \\
\text { Scenario evaluation }\end{array}$ & & $\begin{array}{l}\text { Implementation: } \\
\text { reccommended use }\end{array}$ & $\begin{array}{l}\text { Mitigation, public } \\
\text { participation }\end{array}$ & $\begin{array}{l}\text { Implementation: } \\
\text { includes monitoring }\end{array}$ & Instrumentation & $\begin{array}{l}\text { Seenario development } \\
\text { and its evaluation. } \\
\text { public participation }\end{array}$ & $\begin{array}{l}\text { Syntheresis: } \\
\text { implementation and } \\
\text { monitoring }\end{array}$ \\
\hline & $\begin{array}{l}\text { Decisioa: should } \\
\text { the landscape be } \\
\text { changed and bow? }\end{array}$ & & Post-project evaluation & Moaitoring & & Monitoring & Implementation & \\
\hline & & & & & & & Monitoring & \\
\hline
\end{tabular}

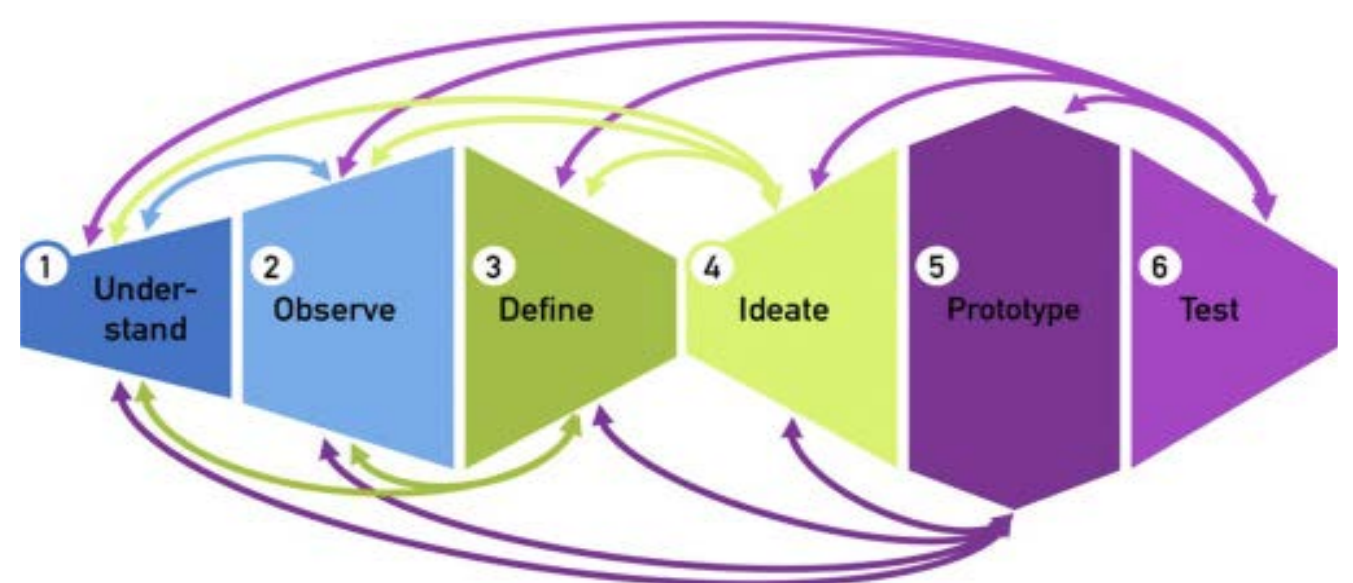

Figure 5. Six steps of design thinking process (Source: Geissdoerfer, Bocken \& Hultink 2016)

\subsubsection{Framework Structure}

Below is a high-level explanation of the framework structure, its phases and what they entail in order to inform future use and adaptation of the framework. A collaborative and iterative approach is suggested throughout 
the application of this framework, which is demonstrated through the methodology of this study. In the following chapter "Conceptual Framework Implementation \& Analysis”, the case study analysis will be applied through this framework to provide an example of its application at the project level.

\section{1) Identifying and Defining the Challenge}

The purpose of this phase is to lay the foundation of the contextual realities and challenges regarding the planning of wildlife crossing infrastructure. In particular, this section must identify:

- If there is an established need for wildlife crossings,

- If there is an opportunity for the implementation of wildlife crossings; and,

- The likelihood for success of that wildlife crossing.

To answer these questions, the availability and access to ecological data is essential. This helps identify where priority or high function habitats are, what species are present and if they are indeed crossing the road and being hit or avoiding the road and therefore creating barrier effects, among other details. Further, ecological data is needed to better understand how and if a proposed crossing structure will make a difference in a given location. This access to ecological data already poses one major barrier to the streamlining of wildlife crossing structures if that data does not exist and evidence based decision making cannot be supported. Other ways of establishing need is studying the existence and extent of designated natural heritage networks/features as well as urbanization and growth trends which may exacerbate habitat fragmentation within a given study area. For this, land use mapping and growth forecasts such as through the Growth Plan in Ontario are helpful. The opportunity for implementation refers to alignment with other decision making processes such as infrastructure project master plans that provide financial support as well as a window of opportunity to apply the evidence of established need and likelihood of success of a proposed crossing structure. This phase intrinsically requires some form of collaboration as it likely requires knowledge sharing and is the best time in the framework to solidify partnerships.

\section{2) Understanding Context}

If there is an established need, opportunity and supported likelihood for success of a potential crossing, the next step in the framework is to establish an understanding of the local decision making context. The purpose of this phase is to situate the researcher in the local geographical and operational setting of the study area in order to 
understand the decision making process. To do this requires building from the ecological context established in the previous phase and identifying key stakeholders, decision making processes and policies that have an interest in and/or influence over the final result of the project. In this phase the application of expert knowledge is particularly useful to gain a more in depth understanding of who the key stakeholders are in the planning of crossing structures and what their roles are, this information is often easier to come by this way rather than forms of literature review.

\section{3) Diagnosis}

The purpose of this phase is to articulate relevant strengths, challenges and opportunities identified in the analysis of the previous phases. This phase goes beyond the identification of relevant decision making processes, stakeholders and policies, and seeks to understand what qualities within these enhance or complicate the implementation of wildlife crossing structures. In this phase the application of expert knowledge is particularly useful to gain a more in depth understanding of the practical realities of planning for crossing structures.

\section{4) Prognosis}

This phase lays out recommendations or a direction for further study to address the findings in the "Diagnosis" phase and provides the transition into the "solution space". This sets the stage for future prototyping of potential solutions.

\section{5) Prototype}

The "Prototype" phase refers to the development and/or refinement of a chosen recommendation(s) for eventual application. This phase should be developed through a collaborative approach, engaging diverse and relevant stakeholders. This phase may help reveal practical and operational barriers to the development and implementation of the prototype and may generate useful knowledge to feed back to previous phases.

\section{6) Test}

The "Test phase" refers to the implementation, evaluation and continued monitoring of the prototype and is an important phase for the feedback of practical knowledge to all previous phases for continued innovation. 


\subsection{Methodological Process and Concepts}

This study takes on a transdisciplinary participatory action research approach to the production of knowledge and uses a triangulation research method whereby three core sources of knowledge are used. These three sources of data include a literature review, policy analysis and subject matter professional expertise derived from participant observation. As the study follows an iterative approach, the three sources inform each other and work within the provided conceptual framework to support knowledge generation and iteration between the various phases (for the scope of this study, phases 1-4). The knowledge generated through this process is derived and applied through a case study analysis within the GTHA to provide a more project level and localized perspective with the opportunity to extrapolate findings to the broader state of science and practice. For further research utilizing the conceptual framework, some form of iterative and collaborative methodology for knowledge generation is suggested but should take the format best suited to the specific context and limitations of that study. Figure 6 illustrates the process of knowledge generation and sharing used for this study. It highlights an iterative process between the three core sources and the system of knowledge sharing between the two key collaborators of the study the EDL and TRCA who will contribute the professional expertise derived through participant observation methods.

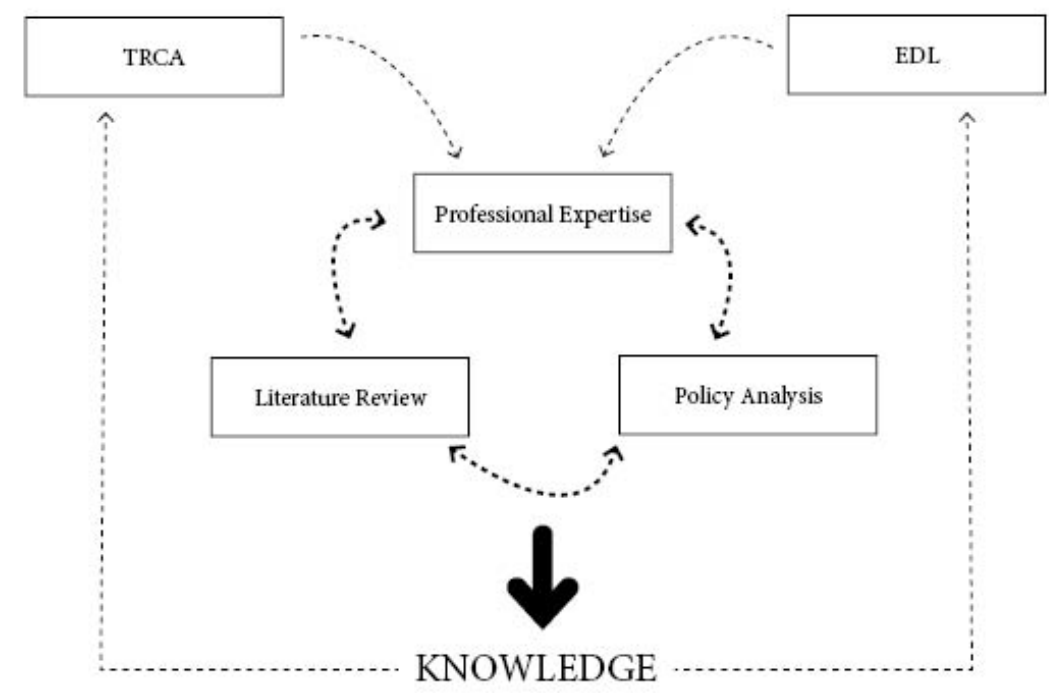

Figure 6. Knowledge generation and sharing process for the study's three key levels of analysis.

The literature review provides the theoretical foundation and scientific justification for the study and provides extensive knowledge regarding best science and practices to transdisciplinary and design approaches within the 
context of landscape planning, governance, EA and the land use planning process. The policy analysis involves a review of various academic and grey literature on the Ontario EA process, land use planning process and relevant legislation for the region specific to the chosen case study area and how they interact with the various stakeholders' roles in the design and implementation of crossing structures. Further, it informs how novel ideas for collaboration and improved process design may intervene and complement the existing process.

The subject matter professional expertise represents a combination of experience from leading thinkers and practitioners across academia and particularly through the public sector at the TRCA through my participation in the CACE project. The CACE project seeks to encourage partnership and process development for undertaking "beforeand-after studies" that typically monitor the effectiveness of various types of implemented crossing structures for habitat and wildlife connectivity in the TRCA jurisdiction. This involvement supported this study in the initial case study selection process as well as the analysis of the case study in the context of the conceptual framework due to its grounding in local context.

As I contributed to the development of supporting material for the CACE project, this experience provided a window into the operational perspective of a key stakeholder, that of a CA, in the process of planning and supporting the implementation of wildlife crossing infrastructure in the GTHA. More broadly, the work with the CACE project provided professional expertise drawn from broader subject matter experts including insight from municipal staff and those working in conservation and environmental assessment.

Access to the opportunity to participate in the CACE project stems from a longer relationship between the road ecology staff at the TRCA and the EDL. As a research assistant for the EDL I began working with the TRCA in the summer of 2017 and conceived of and developed this study collaboratively over the fall of 2017. In the execution of this study, I worked at the TRCA at their office once a week beginning in December of 2017 until April of 2018. These work days were to help with my involvement in the development of the CACE project and to provide me with exposure to the more day-to-day realities of planning for crossing structures in the context of a CA. Activities during these work days included drafting proposal documents for regional municipalities in support of the CACE project, preparing a review of terrestrial passage evaluation processes in other CA jurisdictions, and attending meetings with TRCA staff from road ecology, GIS and EA departments.

\subsubsection{Transdisciplinarity \& Participatory Action Research}


Transdisciplinary action research is useful in answering complex questions about broad issues, exploring disciplinarity and professional relations and for finding solutions to broad, wicked problems that are beyond the purview of any one discipline (Godeman 2008). As such it is well positioned to embody the broad methodological framework for this study. Participatory action research is a form of action research which attempts to solve real-world problems while contributing to the development of general theory and knowledge to the field of inquiry (Eldin \& Levin 1991). It is based on valuable knowledge about the operation of a system or organization developed from extensive experience in a field of practice (Newman 2000: 24). In action research, researchers consider questions and problems from the perspective of practitioners within a particular local context and bounds the research to this local context (Argyris \& Schön 1991). Participatory action research builds upon this to include practitioners themselves as subjects and co-researchers (Argyris \& Schön 1991). The strengths of participatory action research is that it is a context bound methodology and therefore more capable of solving real world problems than abstract theory alone and is a powerful tool in facilitating organizational learning (Whyte et al. 1991). This then makes sense in the context of addressing the action gap in landscape connectivity and wildlife mobility. My study applies this logic by exploring the interaction between professions and professional roles as well as how this operates in the political and legislative structure of the GTHA.

\subsubsection{Participant Observation Methodology}

This professional expertise will be generated and incorporated into the process using a participant observation methodology. A method traditionally used in sociological research in the field of cultural anthropology, participant observation involves that a researcher adopt a role within the action sequence of the observed process (Friedrichs \& Lüdtke 1975). An important distinction should be emphasized between the applications of this method in my study compared to the fields of sociology. Unlike this field, my work seeks to identify and interpret professional expertise, not cultural or personal perspectives. In other words, information that would be common knowledge to others participating in a similar professional role. As such, some of the characteristics, concerns, and advantages of participant observation may differ in the context of this study, however, it will be discussed how this method indeed is applicable and beneficial.

Jorgensen (1989) describes a number of scholarly problems in which the participant observation method may be appropriate, of these a few seem particularly relevant to the challenges of addressing the action gap in landscape 
connectivity and wildlife mobility research: i) there are important differences between the views of insiders as opposed to outsiders, ii) the phenomenon is somehow obscured from the view of outsiders, and iii) the phenomenon is hidden from public view.

The first problem can be interpreted in the context of this study to be the difference in view between the field of practice (e.g. practitioners as insiders) and that of academia (e.g. researchers as outsiders). This has been well referred to in the literature in the previous sections that scholarly research on the importance of landscape connectivity and the effectiveness of wildlife crossing structures is limited in its influence on real-world problem solving if there is a disconnect with the fields of practice expected to implement these findings. Further, this might also refer to the difference in view between various fields of practice themselves including transportation, engineering, ecologists, planners, researchers, politicians and the public who all have competing priorities for the environment as well as different levels of understanding of what is important, why, and how problems are to be solved. The second two problems provided by Jorgensen (1989) may reflect the obscured and not well understood process for planning and implementing wildlife crossing structures. This is not to say that the decision making processes involved, such as the environmental assessment process, municipal budgeting, policy review, planning process are not publicly accessible, because they are and require public input. In the case of the TRCA and other conservation authorities such as Credit Valley Conservation, the process of implementing crossing structures is well articulated and available to the public through agency documents. Despite this, the process may still be confusing for some outsiders, those without expert ecological, engineering, planning and/or process-related expertise, making it difficult to find the "start line", who is involved and what to do.

Participant observation can be viewed as a more holistic, immersive, less researched and unstructured version of the research interview. Friedrichs and Lüdtke (1975) propose that participant observation may be more suitable than interviews for research on complex processes involving many different actors which is a suites the setting of this research project. Further, this methodology may be used alongside more formal interviews to inform the content and structure of the interview and enhance the resulting outcome (Friedrichs \& Lüdtke 1975). This may be of particular interest to the EDL which is utilizing interviews in other facets of their work. Other relevant advantages to the participant observation method include the identification of processes and operational knowledge which could be otherwise difficult to extract through standardized, repeated interviews (Friedrichs \& Lüdtke 1975). 
A key disadvantage and concern with participant observation is that the unstructured nature of the method limits the objectivity of the research (Friedrichs \& Lüdtke 1975). However, Friedrichs and Lüdtke (1975) suggest that this opinion is based on a perspective of objectivity which is too narrow and hinged upon measurement of an a priori nature which can be incompatible with this form of research. Instead, they suggest that a better measure of objectivity in participant observation is in the relationship between the method and the object of study and the possible intersubjectivity of these findings (Friedrichs \& Lüdtke 1975). It is acknowledged here that full objectivity cannot be guaranteed, but through the application of transdisciplinarity and iteration, the findings from this study have been

continuously evaluated and assessed by the collaborators at the TRCA and EDL and corroborated through literature review and policy analysis to reduce personal subjectivity.

Jorgensen (1989) identifies some avenues for data collection through participant observation. For the purpose of this study the use of casual conversations, more in-depth but informal and unstructured interviews among participants at the TRCA as well as attending group meetings were used. Detailed notes were recorded for each of these activities as well as on general experiences within the process indicating content and context of the activities and the process of the project. The combination of participatory action research and participant observation are more common in the fields of sociology, however there is precedence to the use of this combination of methods in the assessment of political and legislative systems to yield valuable and practical insight in the context of the GTHA and York Region (see McCarthy et al. 2010).

\subsubsection{Stakeholder Scan Methodology}

Understanding the stakeholders involved in a complex system, who they are, what their role is and their degree of influence in solving problems within these systems is an important asset for those looking to diagnose and explore alternative solutions to such problems. Stakeholder mapping, or stakeholder visualization, is a process that allows for the identification, management and engagement relevant stakeholders in a certain process (Walker et al. 2008). This has been shown to be particularly useful in project management in highly complex problem solving activities (Walker et al. 2008). This is may prove very useful for streamlining the planning process for wildlife crossing infrastructure as general awareness of the process itself and who is involved can be confusing or obscure to those of different disciplines and professional roles. As such, a stakeholder scan exercise has been incorporated into the research framework to contribute to phase 2 "Understanding Context”. The purpose is to help identify key disciplines 
and the actors within these disciplines involved in the planning and implementation process of wildlife crossings. It will describe the role, contributions and importance of the various disciplines' and agency expertise and influence over the final result in the context of the case study.

Stoney and Winstanley (2001) explore the challenges with "stakeholding” and suggest that the practice can be confusing and subjective due to differing perspectives and motives of the researcher. Therefore, they advise it is critical to clarify and justification the basis for determining what a valid stakeholder is in the context of the research

being performed in order to ensure ontological perspectives are clear (Stoney \& Winstanley 2001). The stakeholders involved in wildlife crossing planning and implementation are thus those who have knowledge of and/or direct or indirect influence over the relevant decision making processes as well as other individuals and groups who may have interests connected to the presence or absence of crossing structures. It should be noted stakeholders can fall into either of these categories, for example the public may have influence over political decision making processes but also may or may not be concerned for wildlife and human road safety. For the purpose of this study, the focus of the stakeholder scan will be on those with direct or indirect influence over relevant decision making processes.

Walker et al. (2008) reviews the use of the Stakeholder Circle ${ }^{(\mathbb{R})}$ tool in the process of stakeholder identification, categorization and prioritization. Of most relevance to the context of this study is the prioritization of stakeholders through consideration of three factors: power, proximity and urgency (Walker et al. 2008). This is used in this study for both categorization, prioritization and interpretation of the stakeholder analysis in the case study. A summary of the three factors are adapted from Walker et al. (2008) to the context of wildlife crossing structures:

- Power will refer to the degree of influence of a stakeholder over the financing, planning, design and construction of the crossing (is it significant or limited?).

- Proximity will refer to how closely associated a stakeholder is to wildlife crossing planning and implementation.

- Urgency will refer to the level of willingness to participate in the process what do they have at stake in the process (what do they have to lose or gain?).

\section{$\underline{2.4 \text { Case Study }}$}

A case study has been incorporated throughout this study in order to maximize the consideration of local context in this analysis, as this is a recurring theme in the literature and may produce more meaningful and practical 
insight for the participants at the project level as well as the broader area of inquiry. The case study has two dimensions: a landscape scale dimension involving York Region as well as a site specific road project located along a segment of Major Mackenzie Drive between Pine Valley Drive and Islington in the City of Vaughan (Figure 7). Both of these perspectives are used to highlight important observations and insights in different segments of this study's analysis.

York Region is the sixth largest municipality in Canada comprising of 1,776 square kilometres and represents a component of the GTHA anticipated to accommodate significant growth and development in the coming years. The 2016 census identified the region's population at 1,186,900 people and is anticipated to reach a growth target of an additional 21,600 people per year until 2031 (York Region 2017). There are nine towns and cities within York Region, the City of Markham and the City of Vaughan are the most populated and expected to absorb the most growth (York Region 2017). The landscape of York Region is predominantly characterized by farmland, suburban development and significant natural heritage systems and significant landform of the Oak Ridges Moraine. Further, a considerable proportion, 69\%, of York Region is located within the protected lands of the Greenbelt Plan area and/or the Oak Ridges Moraine Plan area (McCarthy et al. 2010). Figures 8 and 9 illustrate the extent of natural features, developable tableland and white belt areas in York Region. York Region also has a considerable amount of high priority crossing areas identified in the TRCA's preliminary assessment of natural heritage functions illustrated in Figure 10. York Region is a strategic choice in case study due to its abundance of natural heritage features, its projected growth, as well as an established relationship with the TRCA in the development of the CACE project.

The site specific dimension on Major Mackenzie Drive is one of three road projects identified by the CACE project as a priority site for Before-After studies through an overlay of preliminary assessment mapping from the TRCA and the York Region 2018 10-Year Capital Plan (see Figure 11). The Major Mackenzie Drive road project will involve a road widening to six lanes and the construction of two bridges over the East Humber River and Purpleville Creek with a capital timeline to commence construction in 2018. The EA for this project has already been completed and the detailed design will include three dedicated dry passage culverts for wildlife crossings. The bridges being built are currently box culverts that will be upsized to bridges to include passage on both sides of the two valley/stream corridors.

Major Mackenzie Drive bisects the Kortright Centre for Conservation a conservation area comprising of 325 hectares. The preliminary assessment by the TRCA designated the East Humber River and Purpleville Creek valleys as having high crossing significance (Figure 12). Data collected by the TRCA in 2016 confirms the presence of a 
number of local species of concern including species of amphibians, small mammals and birds. This site was chosen for further analysis because of its earlier timeline (completion by 2020) and completed EA which will be studied in the later analysis of this report as well as its ecological significance highlighted by existing data and policy.

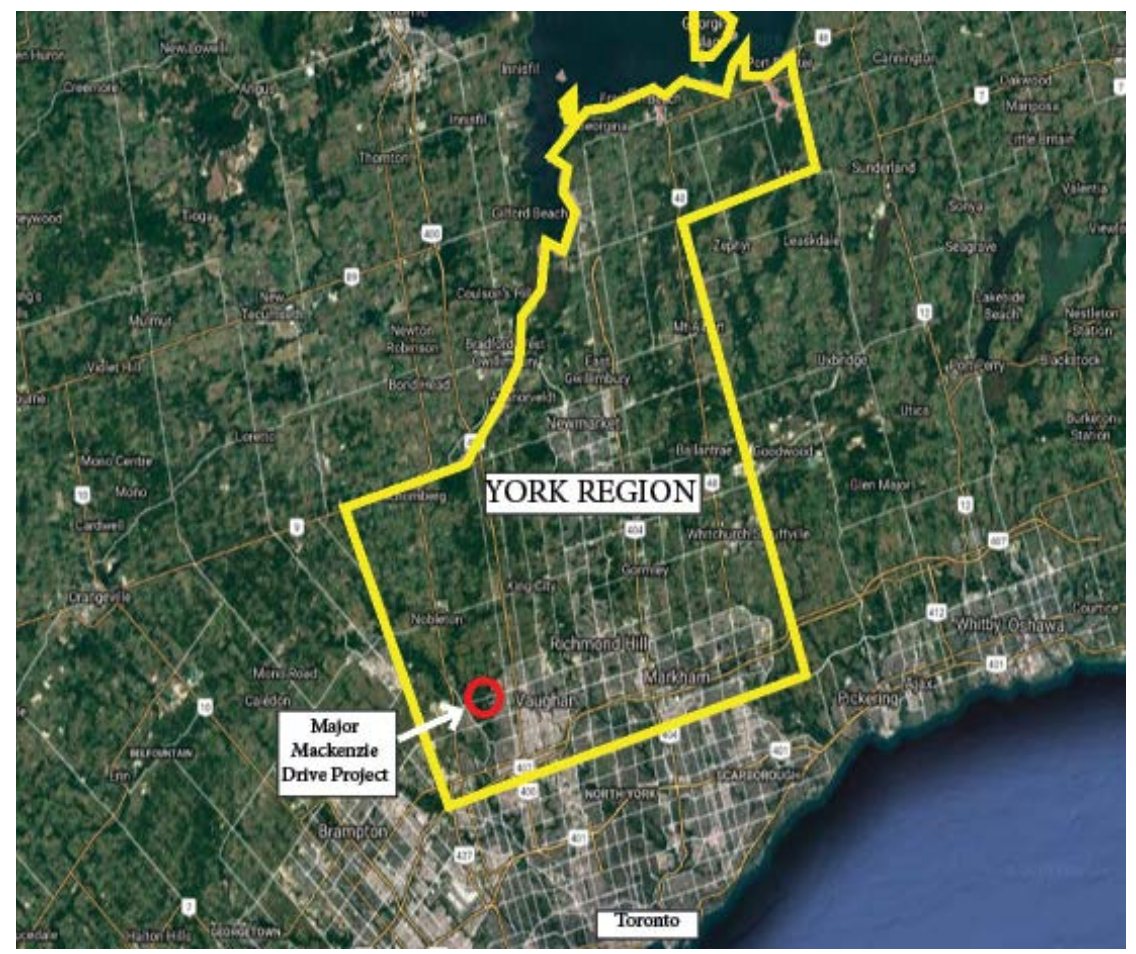

Figure 7. Case study context (Adapted from Google Maps 2018)
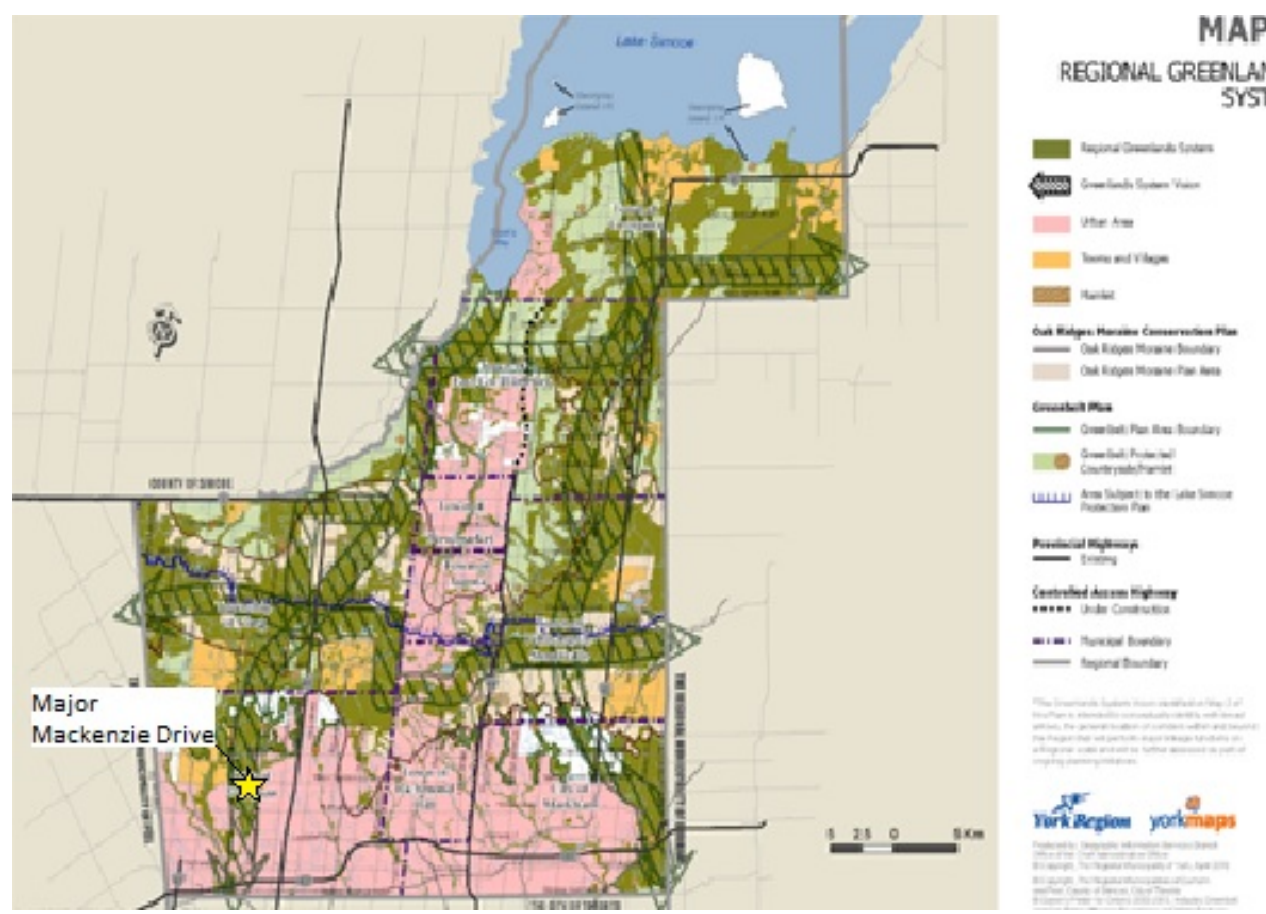

Figure 8. York Region Official Plan Map 2 illustrating the Regional Greenlands System (Source:York Region 2010) 


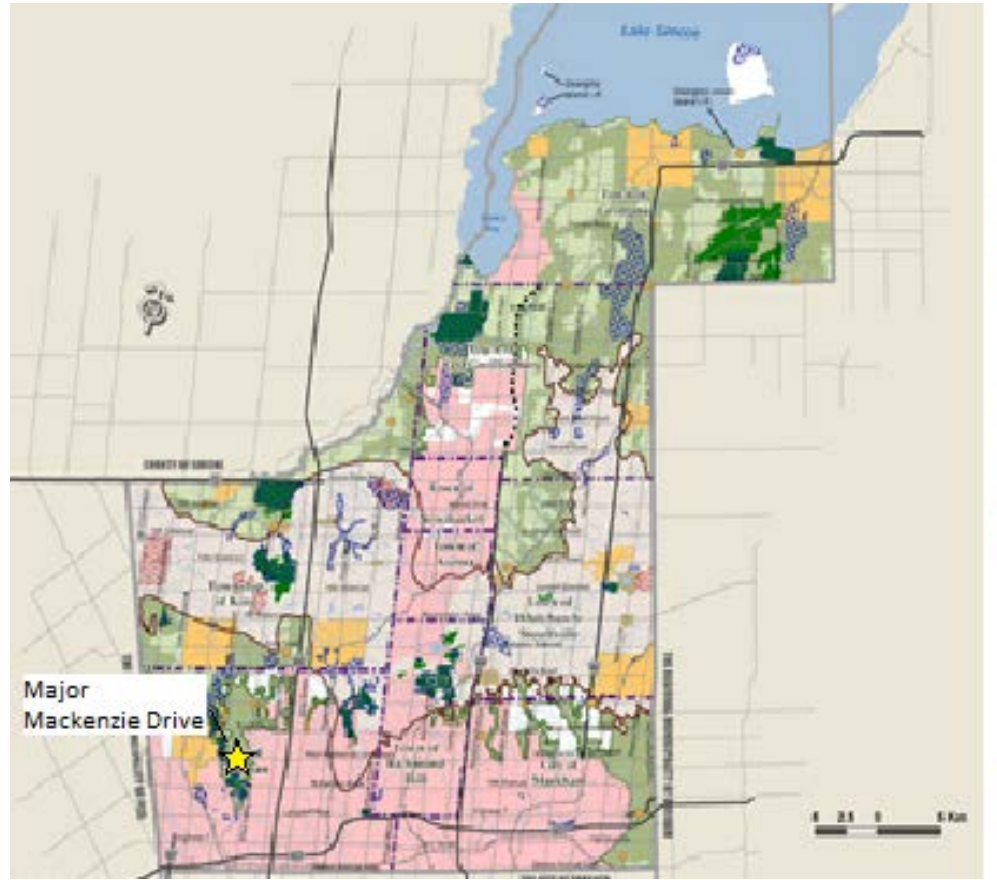

MAP 3

ENIRONGENTALIY SIGNIFICANT AREAS and AREASS $d$ NATURRAL and SCIENTIFIC ENTEREST

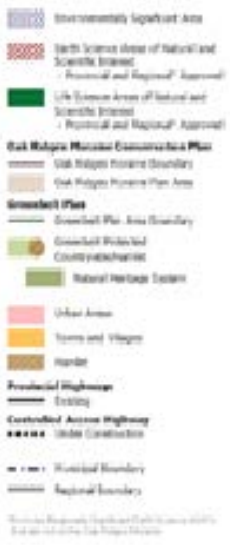

Figure 9. York Region Official Plan Map 3 illustrating areas of environmental and scientific significance (Source: York Region 2010)

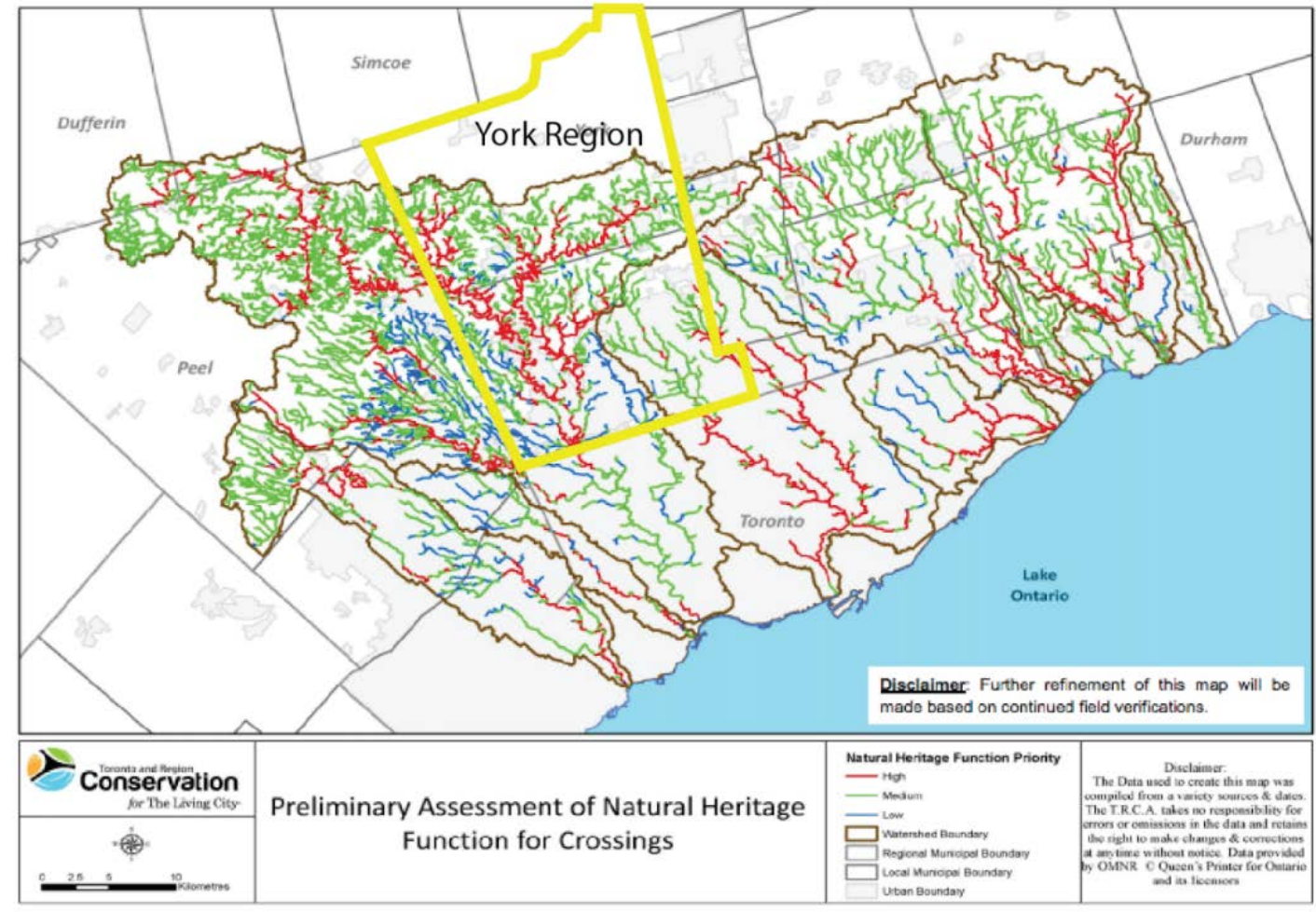

Figure 10. TRCA's preliminary assessment of natural heritage functions reflecting a gradient of priority for crossings (i) high (red) are deep valleys with high priority for habitat and connectivity, (ii) medium (green) are shallow valleys with high existing and potential habitat and connectivity potential, and (iii) low (blue) reflects low priority for habitat and connectivity (adapted from TRCA 2015). 


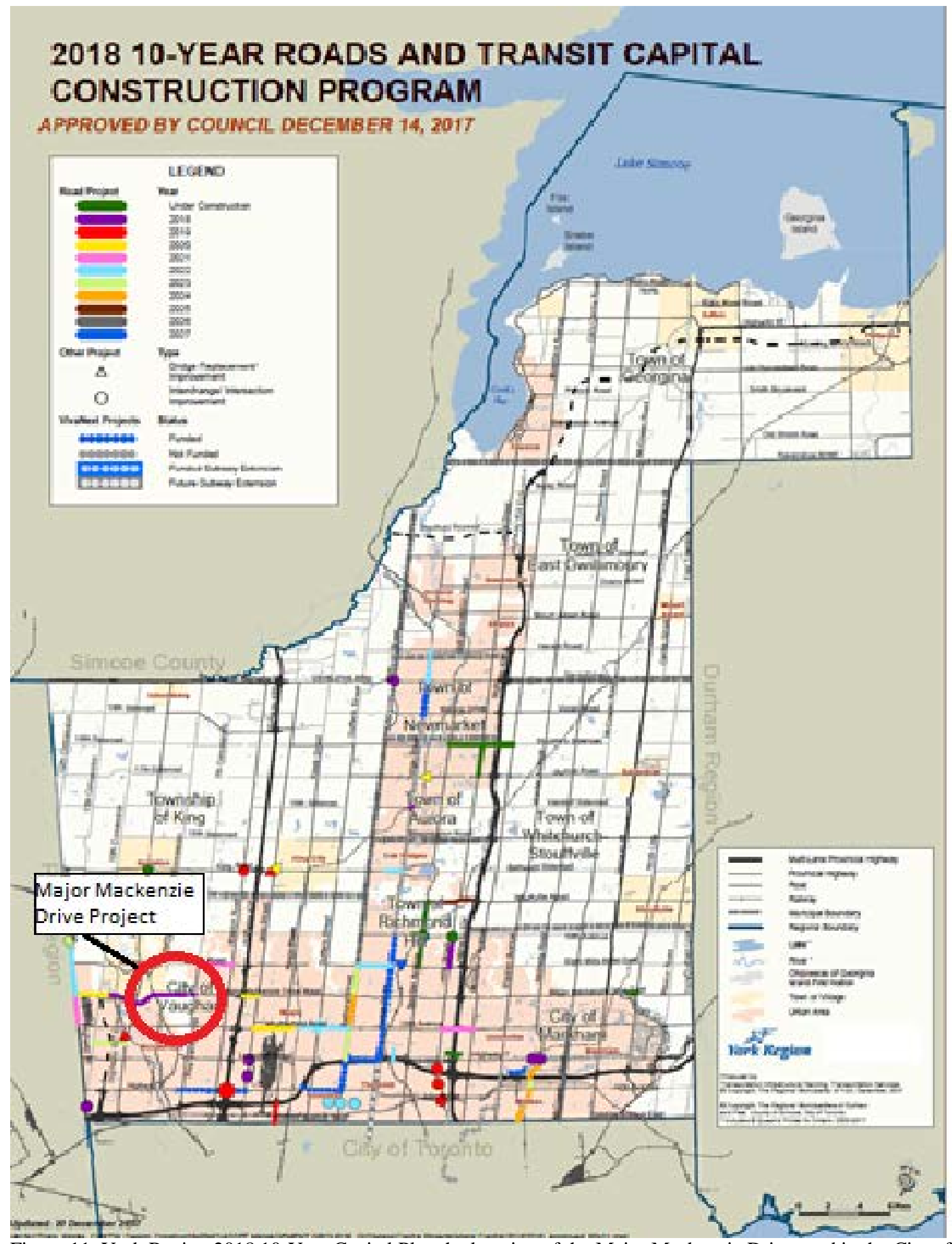

Figure 11. York Region 2018 10-Year Capital Plan the location of the Major Mackenzie Drive road in the City of Vaughan (Adapted from: York Region website) 


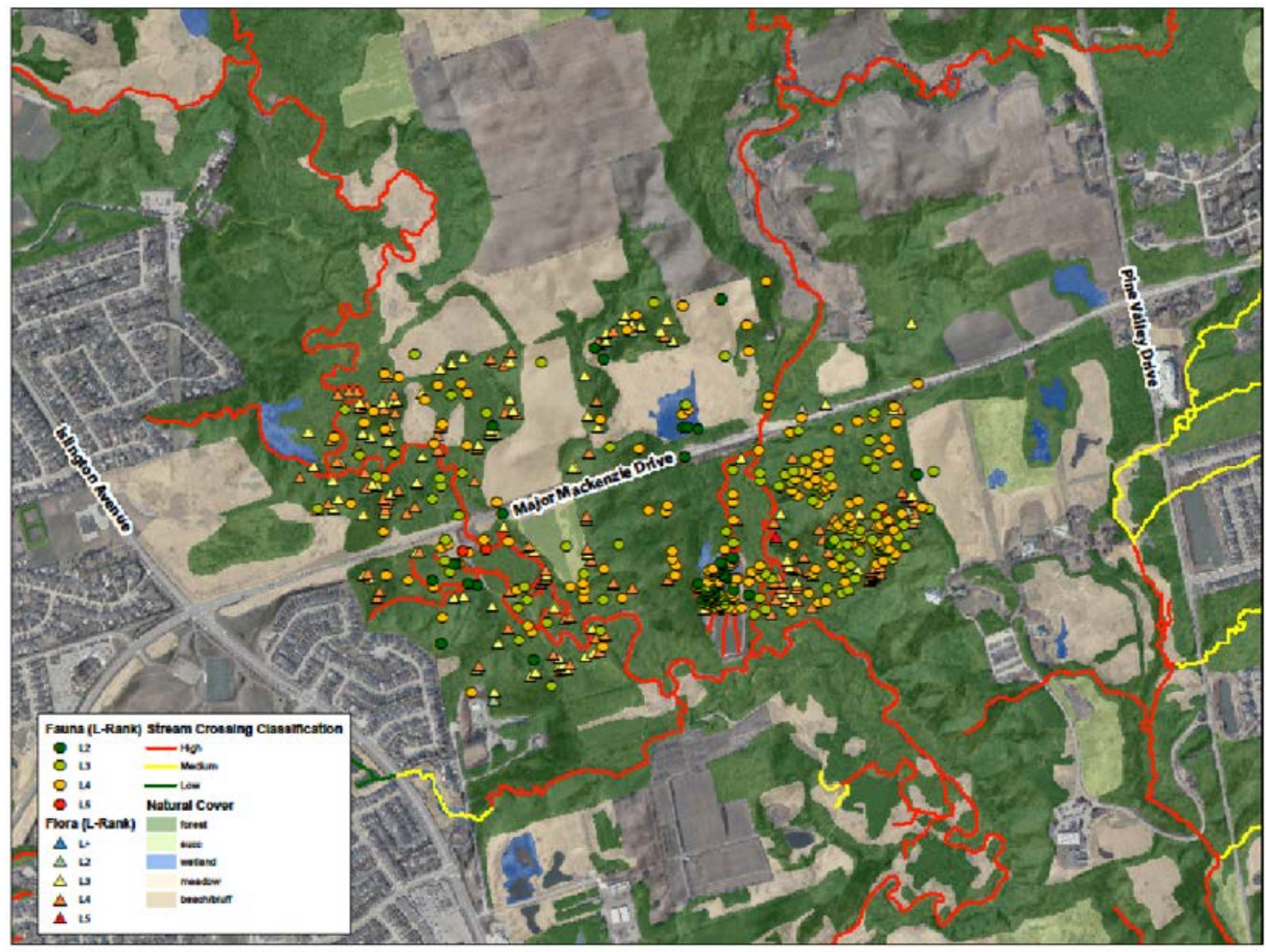

Figure 12. TRCA data crossing classification for Major Mackenzie Drive. The stream crossings on Humber River and Purpleville Creek are classified as high priority with many species of fauna identified on both sides of the road (Source: TRCA data) 


\section{CONCEPTUAL FRAMEWORK IMPLEMENTATION \& ANALYSIS}

\subsection{Identifying and Defining the Challenge}

Drawing from the analysis conducted already in previous sections of this study, both the regional and project level dimensions of the case study have an established need, opportunity and reason to believe there the resulting crossings will be successful.

The existing data compiled for the preliminary assessment which has resulted in the map in Figure 10 as well as the TRCA's Crossing Guideline (2015) has clearly identified that there is a need for wildlife crossing structures and even where in their jurisdiction they are needed most. York Region is part of this data and is further highlighted as an area in need of wildlife crossings from its significant extent of natural heritage features and Greenland systems throughout the regions in addition to being the focus of considerable growth and development projected for the coming decades. The Major Mackenzie road project clearly established need through its location within and in close proximity to a variety significant environmental features. Further, in the EA study for the project, stakeholders including the public and the TRCA explicitly emphasized the need for wildlife crossings in this area.

Through the CACE project, the opportunity for wildlife crossings both from the regional and project level scale was established from the release of the York Region capital projects plan in 2018 which identified specific road projects to be implemented. In conjunction with the existing ecological data, this identified three opportunity sites, one of which was Major Mackenzie Drive. This opportunity was created due to the establishment of political commitment to the road project and through this the availability of funding to implement the project. This opportunity was strengthened, through the example of the CACE project, particularly at the regional scale because of the development of partnerships with York Region, the proponent of these road projects, who has shown interest and proactiveness in enhancing road ecology objectives.

Finally, the proposed opportunity for wildlife crossings at the Major Mackenzie Drive suggests that there is a likelihood of success because of the quality of the habitat and presence of species that would use the crossings. This criteria is best addressed at this project level as the regional scale does not account for the localized conditions which actually suggest if a proposed crossing will actually made a difference. This component is however limited as there is not a well-established dataset localized in this area to inform on the effectiveness of the crossings themselves. The CACE project will work to directly address these uncertainties and support better evidence based decisions around crossing structures in the future. Although the Major Mackenzie Drive project has already completed its EA, it was 
successful in producing the preferred outcome due to the existing data, opportunities and reasonable belief of success of the structure. Through the CACE project it will contribute to long term monitoring of the effectiveness of crossing structures in York Region to better inform future opportunities.

\subsection{Understanding the Context}

\subsubsection{Stakeholder Scan}

The range of stakeholders involved with planning and implementing wildlife crossings structures spans all levels of government in Canada and the level of involvement of the diverse body of stakeholders is dependent on the road type, the habitat and species affected by the road project. For a broader exploration of the stakeholders involved in wildlife crossings in Canada, refer to the work of Elton (2015). For the purpose of this study, only a selection of these stakeholders are explored in depth as to adequately address the local context of the selected site and reflect those that best embody the three identification principles outlined in the methodology section: power, proximity and urgency. The findings from this process has identified two perspectives on stakeholder identification and prioritization: through disciplinary and agency categories.

\section{A. Disciplinary Categories}

Disciplinary categories in this context refers to broad disciplines that are present across various organizational and jurisdictional settings. Four primary disciplines were identified as being particularly influential in the planning and design of wildlife crossings including: Ecology, Planning, Transportation and Civic. The Planning, Transportation and Civic disciplines can be seen as having more power in their role as stakeholders as they can have a strong influence in the decision making process and the actual application of the insights generated by the Ecology discipline. These serve as broader categories which could be applied in other contexts and are also supported in the literature as important sectors for collaboration to solve complex ecological problems.

i. Ecology is the discipline with the highest proximity and perhaps holds the highest degree of urgency in ensuring habitat connectivity. It provides profound insights into ecosystems functions, their value to broader ecosystem health and to society, as well as how to protect and enhance of ecological integrity. (Ahern 2012; Holling \& Goldberg 1971/2014). The power of the Ecology discipline is dependent largely on their agency affiliation, which will be discussed below. 
ii. $\quad$ Planning has a strong understanding of urban form and patterns of urbanization and the dynamic processes that result in these forms and patterns (Ahern 2012). Planners are well positioned with a central role in the application and formulation of policy regarding land use and development as well as an influential hand in communication between all stakeholders (Ahern 2012; Holling \& Goldberg 1971/2014). Therefore planners hold a fairly high degree of power in the outcome of decisions, but have varied degrees of urgency and proximity to the topic of wildlife crossings largely influenced the context in which they operate. For example a planner in the context of environmental planning, transportation planning, development planning and policy may all have different priorities and proximity to the topic area and are largely influenced by their field.

iii. Transportation includes transportation planners and engineers who hold a high degree of power particularly over the design of crossing structures and road planning. The degree of proximity and urgency for this category can be seen from two angles. First from an ecological perspective in that Transportation has a high degree of proximity in the problem of landscape connectivity and wildlife mobility as transportation networks are a major cause of habitat loss and fragmentation, and by extension, biodiversity loss. This suggests that Transportation should also have a high degree of urgency due to the pace of urbanization in York Region. On the other hand is Transportation's perceived role in city building, whereby their role is exclusively dedicated to human mobility. This view better reflects how Transportation is perceived in the real world.

iv. The Civic category encompasses actors with a stake in the political decision making process and includes the public, indigenous peoples, elected officials etc. This category may have varied degrees of urgency and proximity to the topic of landscape connectivity and wildlife mobility depending on the interests and values of the member or group. Civic also has a high degree of power due to its influence on processes like budgeting, election of officials, approvals and decision making. It should be noted that the actual influence of Civic power largely depends on the degree to which these sub-groups exercise this power. This suggests that engagement, public education as well as barriers to participation in civic processes are an important consideration. 


\section{B. Agency Categories}

The consideration of agency categories builds from the discussion of disciplinary categories but applies a more project-level lens for the case study. The key agency categories include: municipality, academia, conservation authorities, external agencies, and the public.

i. Municipality (York Region): Municipal governments are a type of local council authority that provides local services, facilities and infrastructure for communities. There are two tiers of municipal governments in Ontario, the Upper- Tier (regional) municipality and the Lower-Tier (local) municipality. The tiered structure is to ensure the most efficient and effective use of resources and public spending. York Region is responsible for the financing and planning of regional road projects, such as Major Mackenzie Drive as well as the development of Regional Official Plan policies for which lowertier municipalities must abide. Key actors within York Region include policy makers, transportation specialists and planners, as well as council.

Municipal Council is the final decision making body for local affairs and sets policies, direction and budgets for the municipality. In this decision making process, value is placed on various priorities and issues. This is particularly significant in the case of guiding policy and capital planning budgets for transportation infrastructure and conservation and restoration initiatives. This places York Region with a high degree of power over the planning and design of crossing structures. Similar to the divide in perspectives on proximity and urgency in the previous section, ecological values are not intrinsic the foundation of these professional roles. York Region's council consists of the elected Mayors of its lower tier municipalities, and as such demonstrates the importance of public perception and local politics on the decisions of York Region.

ii. Publics: The participation of diverse Publics (indigenous communities, individuals, community groups, and landowners) are invaluable to the protection of natural habitat and wildlife and their input is important in both the environmental assessment and planning processes and are legislated under the Environmental Assessment Act and the Planning Act. Publics can have a high degree of proximity and urgency to the topic of wildlife crossings in that they are both impacted through road safety concerns as 
well as their personal value and awareness placed towards nature in general and the impact of roads on wildlife. The latter varies greatly across the population. Publics can exercise a high degree of power as well if they exercise their civic power to influence elections and political decisions or through self organization to implement crossing solutions as is seen in Long Point, Ontario. Landowners are considered here as a subcategory of Publics as they inevitably are involved in the implementation process of crossings. Increasingly developers are required to consider crossings for approval in the EA process.

iii. Conservation Authorities: Conservation Authorities (CAs) are local watershed management agencies that operate in partnership with all levels of government, landowners, communities and other organizations to provide services and programs that protect and manage impacts to the natural environment and risks to life and property from natural hazards. CAs are given legal authority through the Conservation Authorities Act and are involved in varied capacities in other provincial legislation that are relevant to the protection of and mitigation of effects to wildlife, including:

o The Planning Act -which provides a land use planning system led by provincial policy. CAs function as a commenting agency in this process, whereas the Municipality is the approval authority.

o Green Belt Act/Plan - a provincial policy document provided with legal authority through the Planning Act to inform decisions regarding land use, natural heritage and natural resource protection. CAs play a technical clearance/regulator role.

o Environmental Assessment Act - Lead primarily by the MOECC, the purpose of this Act is to provide for the protection, conservation and wise management of the environment in the occurrence of public sector projects and major private sector projects. CAs provides technical clearance in this piece of legislature and through the role of regulators in the EA process.

CAs are the stakeholders supplying ecological expertise, data and direction to the other stakeholders. CAs hold a high degree of proximity and urgency with regard to wildlife crossings as it is their mandate to ensure the protection of ecosystems and species. They may exert a high degree of power as a regulatory body through the processes listed above, however their power in effecting higher-level decisions such as capital budgeting or policy formulation can be limited. 
iv. External Agencies \& Academia: External agencies include academia and non-profit organizations with close proximity to the topic of wildlife crossings and connectivity. Examples of this include the Ryerson University’s Ecological Design Lab and the Ontario Road Ecology Group, more specific to the case study, an example could include the Kortright Center for Conservation. These organizations have limited power in the actual decision making processes behind wildlife crossing structures but they are important in the generation of knowledge to inform decision making and develop new and innovative solutions to problems. They share a high degree of urgency with CAs as they hold strong ecological values. In addition, in the context of transdisciplinary collaboration, they provide expertise and labour that can enhance the power of other agencies when resources are lacking.

This exercise demonstrates the interrelationships between these disciplines and agencies and how their expert knowledge and experience, decision making processes and subsequent outcomes are not contained to their own practice in which they operate but have implications for the others as well. This extends to the implications on the collective challenge of landscape connectivity. The value of transdisciplinary collaboration between these disciplines and agencies suggest they can complement each other in a way that closes the action gap in planning for more connected landscapes. Ecology, CAs and External Agencies have considerable expertise in what the problems are and how to avoid and mitigate road impacts. Whereas the other disciplines and agencies have a strategic advantage in turning these insights into real action.

\subsubsection{Policy Context and Scan}

Opportunities for wildlife crossings are typically captured through the Environmental Assessment Act and Planning Act processes for specific infrastructure projects such as road works as well as land development (Elton 2015, TRCA 2015). As such, it is important to understand the legislative contexts of these two processes in Ontario and the GTHA. The governance structure in Ontario follows a principal-agent model in which planning, management and financing responsibilities for services are distributed between provincial and municipal governments. This influences the planning, management and financing of road projects and related mitigative measures to surrounding habitats. There are different classifications of roads in Ontario including highways which fall under the jurisdiction of the Province of Ontario, regional roads fall under the jurisdiction of York Region (the upper-tier municipality) and local roads and streets are the responsibility of the local municipalities such as the City of Vaughan. While processes that fall under the Planning Act are directed towards the broader topic of land use and development, they do inform 
the need for and siting of infrastructure. The EA process provides a more project-level oversight over the environmental impacts of an infrastructure project such as a road. It is used to evaluate and predict the environmental impacts of a proposed project pre-emptively in order to ensure a decision making process that leads to the most desired outcome (CEAA 2014). It also provides a framework for participation and consultation with the public and other commenting bodies. The resulting EA documents are legally binding.

The two types of EAs performed in Ontario include Individual EAs and Streamlined EAs. In the context of road planning, Streamline EAs are typical. Streamlined EAs are used for "routed projects that have predictable and manageable environmental effects" and follow a self-assessment process that is pre-approved by the Minister of Environment and Climate Change (MOECC) (Government of Ontario 2015). Streamlined EAs are further classified by project type which share similar characteristics and effects. These classifications, one of which specify road projects, are addressed through a Class EA planning document which outlines the EA process for the particular project type. Class EAs are further classified into 'Schedules' or 'Groups' based on the significance of environmental impact and level of consultation required (Elton 2015). The Major Mackenzie Drive road project involved a Schedule C Municipal Class EA (MCEA).

Although there are numerous provincial legislation that are influential in the implementation of wildlife crossings, only those directly applicable to the case study will be examined here (for more exhaustive analysis see the work of Elton (2015) and McCarthy et al. (2010)). Figure 13 illustrates the land use planning process and the EA process and their connection to wildlife crossing structures simplified across three key stages.

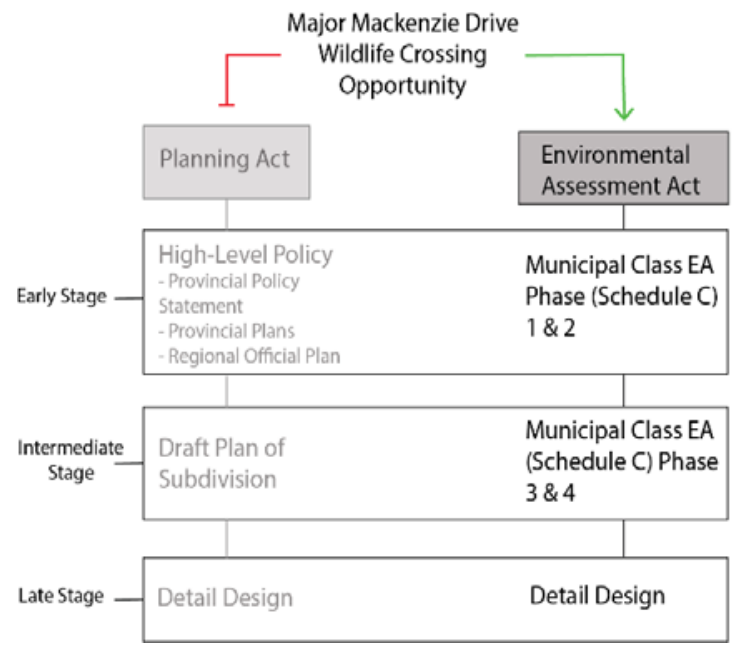

Figure 13. Illustrates the three general stages the land use planning and EA processes. The EA process is the process through with the opportunity for wildlife crossings were captured for Major Mackenzie Drive (adapted from TRCA 2015). 


\section{Early Stage}

The early stage in the EA and land use planning process involves the establishment of the need for wildlife crossing infrastructure. The Provincial Policy Statement (2014) (PPS), Greenbelt Plan (2017) and the York Region Official Plan (2010) (YROP) are the key planning instruments in this stage for the identification of a need for crossings as well as a design and implementation process for the Major Mackenzie Drive case study location.

The PPS is the ultimate guiding document for land use planning in Ontario and seeks to direct land use decisions to "meet the full range of current and future needs, while achieving efficient development patterns and avoiding significant or sensitive resources and areas which may pose a risk to public health and safety” (MMAH 2014, pg. 4). The PPS provides direction for the Greenbelt Plan 2017 a provincial act which works to protect lands of ecological and agricultural significance within the Greenbelt area. The Major Mackenzie Drive case study is located within the Greenbelt boundary and is designated as "Natural Heritage System" and is therefore subject to all related policies within the Greenbelt Plan. The York Region Official Plan provides policy direction to guide new development in the region and represents the most localized and granular planning policies to the case study reviewed in this study. The Major Mackenzie Drive project is identified within the Greenbelt Plan Area on Map 1 - Regional Structure, Regional Greenlands System in Map 2 of the York Region Official Plan (Figure 14), and is further identified as an "Environmentally Significant Area" and a "Life Science Area of Natural and Scientific Interest” in Map 3 of the York Region Official Plan (Figure 15). All these policies under the Planning Act serve to support the identification, protection and restoration of significant ecological features and their functions through the land use planning process. This policy therefore further supports the establishment of need in the previous phase of this framework and suggests opportunity as well in that there are policies in place and therefore clear motivation from a governance perspective to protect these natural features. 


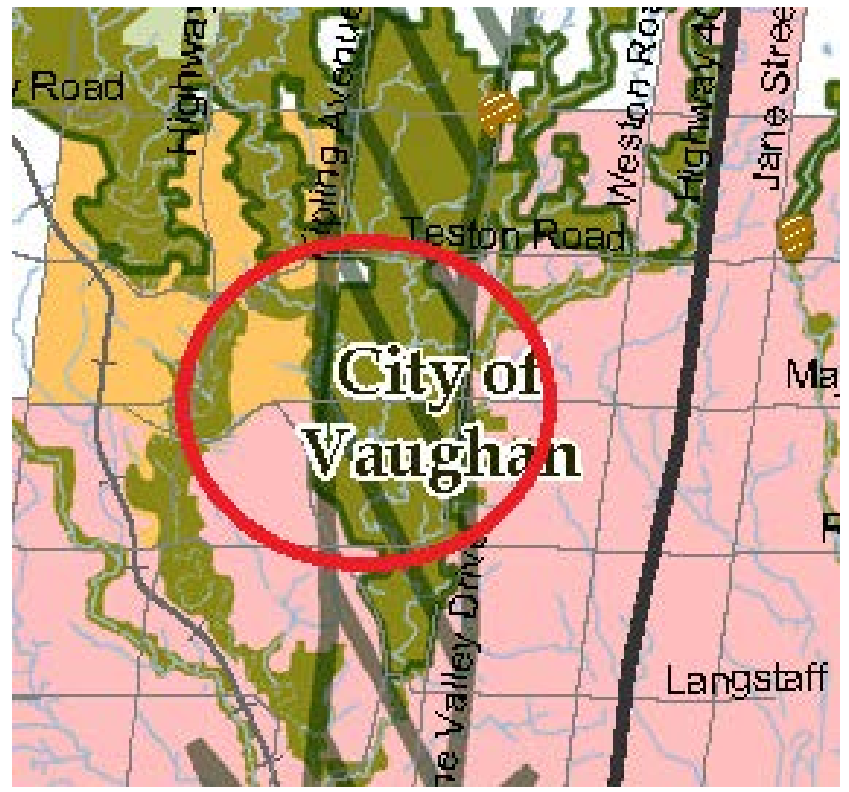

\section{MAP 2 \\ REGIONAL GREENLANDS \\ SYSTEM}

Figure 14. York Region Official Plan Map 2 excerpt showing the extent of the Regional Greenlands System along Major Mackenzie Drive (Adapted from York Region 2010).
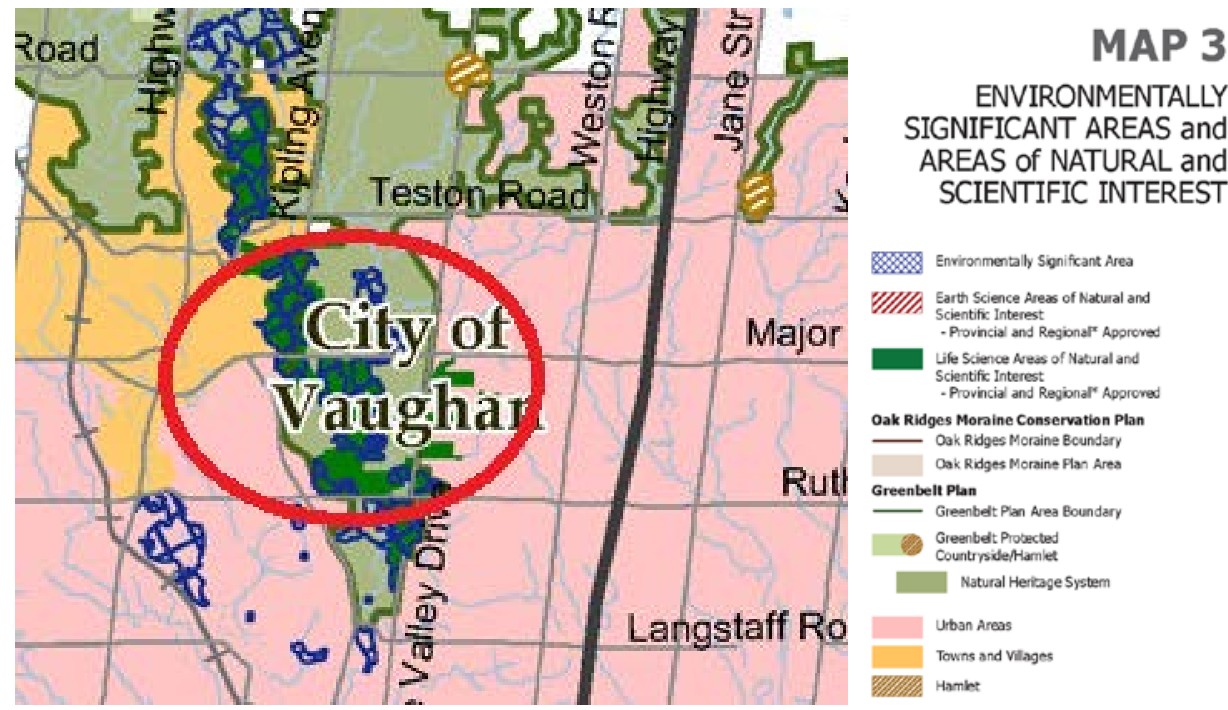

Figure 15. York Region Official Plan Map 3 excerpt showing the extent of ESA and ANSI designated natural areas along Major Mackenzie Drive (Adapted from York Region 2010).

The language in these high-level policies surrounding the concerns and objectives of road ecology and habitat connectivity are fairly supportive but do not provide traction in their application to connectivity across linear infrastructure. These policies typically defer to the EA process in the case of proposed transportation infrastructure projects, as with the Major Mackenzie Drive case study, which does not typically fall within land development policies and processes of the Planning Act. This shifts the responsibility for capturing opportunities for wildlife crossings in transportation infrastructure projects almost entirely on the EA process. The intermediate and late stages of the land 
use planning process are not discussed further due to that in this context, the process is limited to either incorporates the findings from the EA or simply are not required to consider the use of crossing structures.

The early stages of EA are characterized by the identification of the problems and opportunities associated with a project and the evaluation of alternative solutions (TRCA 2015). For Major Mackenzie Drive, this is the Phase 1 and 2 of the MCEA process. Public input, including that from CAs are incorporated to inform conceptual alignment and location of the infrastructure to minimize environmental impacts. Although the alternatives are conceptual, the early stage is critical in the outcome of a crossing structure to ensure appropriate budgeting for the design that will best accommodate the ecological demands for the structure (TRCA 2015; Elton 2015; McCarthy 2010).

The need for crossing structures were identified in due to the high ecological significance of the area along Major Mackenzie Drive between Islington Avenue and Pine Valley Drive. The road widening would effect a number of designated ESAs, Life Science ANSIs as well as a collection of wetlands under consideration for the designation of Provincially Significant Wetland. Comments were received from this phase of the EA process by both the public and the TRCA regarding the importance of habitat connectivity and the consideration of wildlife crossing infrastructure.

\section{Intermediate and Late Stages}

The intermediate and late stages include phases 3 and 4 of the MCEA. Through these phases, impact assessments for natural heritage function, among other areas of concern, are completed. The findings of these impact assessments along with considerations for cost, social impact and benefits to the transportation system inform the eventual selection of the preferred alternative and the refinement of detailed design for this alternative. Public input, including comments from the CA are continued in these stages, with the CA provides final approval of the designs through the permitting process.

In the Major Mackenzie Drive case study, more detailed comments regarding the design of crossing structures were made by the TRCA and incorporated into the detail design of the road plan. The alternatives were narrowed to two options for the widening of Major Mackenzie Drive: (1) to widen the road equally on the north and south side of the existing road, or (2) to widen only along the north side of the road. The latter option was determined to be most preferred as it minimized the negative ecological impact of habitat loss to the Kortright Conservation Area to the south. To mitigate the impacts to terrestrial species, the final design included three new $4 \mathrm{~m}$ by $2 \mathrm{~m}$ culvert crossings 
and two span bridges, which together accommodate the passage a range of small to large species and provide trail linkage for human use.

\subsection{Diagnosis}

In this "Diagnosis" phase, the findings collected through the policy analysis, literature and subject matter expertise were synthesized and applied to a discussion of strengths, challenges and opportunities moving forward in the context of York Region and the Major Mackenzie Drive road project. The findings of this phase will inform future application as tangible planning outcomes for the case study area.

\subsubsection{Strengths}

It is evident through all components of analysis that the EA process represents the framework in which the CA has the most power and authority in proposing wildlife crossings in the road planning process and is really the process through which most opportunities for wildlife crossings are realized. This fact can also be interpreted as a weakness, but that will be discussed later in this discussion as a challenge within the land use planning process. In terms of collaboration, the EA process is in theory a collaborative process, it requires incorporation of insight from a diverse set of stakeholders ranging from the public, to regulatory agencies and commenting bodies as well as detailed impact assessments. CAs, the stakeholder with a high level of proximity and urgency for mitigating WVCs are provided with a higher degree of power over final approval through the permitting process in the EA process. This can be seen in the Major Mackenzie project EA documents where TRCA comments clearly state a permit cannot be issued unless it meets their requirements. In the Major Mackenzie Drive EA study, the proponent worked closely with the TRCA and other members of the Review Committee throughout the early, intermediate and late stages of the process. These qualities all support collaboration, and in the case of the Major Mackenzie Drive project, contributed to the result of the preferred outcome.

The TRCA has available a good landscape dataset that creates a clear ecological portrait of their jurisdiction in relation to road networks for their preliminary assessment process. This data is crucial for justifying the need for wildlife crossings, identifying and selecting sites for these crossings and monitoring their effectiveness post construction. In this respect, the TRCA already participates in a form of transdisciplinary collaboration as this data was compiled with the help of multiple other partners including municipalities and landowners who shared data or permitted access to private lands for field studies. The CACE project builds from this existing data set and aims to 
further enhance this data and support long term monitoring and represents an example of a collaborative partnership with York Region over a shared road ecology objectives.

Although the Major Mackenzie Drive EA has already been completed and the potential applying the conceptual framework to contribute to the final outcome is missed, the CACE project will retain the benefit of conducting Before-After studies to strengthen localized data on crossing structure effectiveness which may be applied in future projects. In terms of the conceptual framework, this is an example of iteration and feedback of knowledge to earlier phases to encourage further innovation and process efficiency.

In addition, the TRCA's Crossings Guideline (2015), a public document, outlines the site selection process and how wildlife crossings with the TRCA fit within the land use planning and EA process. Beyond the TRCA, other wildlife crossing guidelines are applicable in the GTHA including that of Credit Valley Conservation, Ministry of Transportation and Ministry of Natural Resources. These public documents together create a resource base to inform actors across various disciplines and agencies on the appropriate design and placement of crossing structures.

Another strength is the establishment of interested partners as demonstrated by the CACE project in which municipal staff from York Region have expressed interest in partnering with the TRCA to pursue their interests and objectives related to road ecology. Further, the TRCA has developed partnerships in academia as well, as demonstrated by this joint study with the EDL. This demonstrates that the establishment of interested partners, an important preliminary step to more collaborative approaches, has already been initiated. This will only enhance the regional ability to streamline wildlife crossing implementation moving forward. On the project level perspective, the Major Mackenzie Drive EA demonstrated how the participation and awareness of the public can also enhance the implementation of wildlife crossings. The EA document for the project identified a strong concern by the public for the protection of the natural features on either side of the road as well as a call for the implementation of wildlife crossing structures specifically for wildlife mobility. The EA also involved a Review Committee of municipal stakeholders as well as the TRCA maintain continued dialogue. This commitment to continued feedback contributed so a positive outcome in the detail design phase of the road project.

Strong leadership in agency roles is another strength both at the project level and more broadly in planning for wildlife crossing infrastructure. In the context of working with the CACE project, road ecology champions at the TRCA were essential to the development of the project and its success moving forward. As there is currently no 
streamlined process for planning crossings, it requires this leadership to push new approaches and engage with external partners such as the EDL and local and regional municipalities.

\subsubsection{Challenges}

The professional expertise validated many of the challenges in planning for wildlife crossings and landscape connectivity in the land use planning and EA process identified in the policy scan and literature review. There is a misalignment in the general EA process timeline and the study timeline requirements for field ecology data collection. Road planning timelines can be turbulent in early stages of planning due to political and budgeting decisions that delay the EA process. This timeline does not align with the need for ecological studies to span multiple seasons and even years to collect data and therefore requires a level of certainty in order to commence studies at the appropriate time to influence crossing design decisions. Comments by the TRCA for the Major Mackenzie Drive project stressed this concern as the TRCA was unable to make detailed comments on the appropriateness of crossing design for the site before a refined alternative solution was established and related impact studies to support them were completed. This demonstrates the importance of ecological data of the study area early in the process to inform conceptual design but also the importance of localized data regarding the effectiveness of crossing structures themselves to encourage a more streamlined process in the long term.

The lost potential to capture opportunities of wildlife crossing structures through the land use planning process is another weakness in the more widespread implementation of crossing structures. As it stands, the policies within the land use planning process provides some dialogue to address connectivity of natural features in land development projects and in the instance of Master Planning, whereby large areas of greenfield lands are developed, opportunity is provided to converge with the EA process as new road infrastructure and transportation planning is coordinated along with land use considerations. These instances may provide an opportunity for transdisciplinary collaboration in early stages of planning to engage with landowners, municipal staff, CAs and the public to inform future development.

Although this case study EA was proactive in addressing wildlife mobility concerns and collaborating with stakeholders, and the TRCA in particular regarding crossing design, elsewhere in the literature on road planning process and EA in the GTHA and in York Region, real barriers to meaningful collaboration are reported (Elton 2015; Yuan 2014; McCarthy 2010). This suggests that this is not a consistent process and is largely dependent on the level of willingness and awareness of the proponent and stakeholders involved. 
It is evident that the road planning process is heavily influenced by politics and individual projects can been clouded with contention, particularly in the early EA process when budgeting and other major decisions are being made. This contention influences the planning of crossing structures as it can act as a barrier to collaboration and knowledge sharing between agencies in individual projects. In this sense, in later stages of the EA or once the EA is completed, collaboration may be more likely to be effective. This may be too late in the process to influence the crossing design outcome for the specific project, but still may encourage innovation and collaboration to benefit future project and develop partnerships to benefit the broader process of collaboration for wildlife crossings. The selection of Major Mackenzie Drive as a case study, was itself a strategic decision as the EA process had been completed. The other two road sections being considered under the CACE study have a longer timeline horizon and as such are earlier in the EA process.

The political climate further complicates wildlife crossing planning as it is turbulent with short term mandates that rarely fit easily with long term planning objectives and funding commitments may change with new priorities decided on by council. The CACE project has a criteria in their site selection process for each project that mentions the likelihood of the road project to change. This reflects this challenge, as budgeting and competing priorities for municipal spending can cause changes to the road project timeline, which then influences the site's priority for field studies by the TRCA. As such the expertise collected through this study also emphasizes the need for more awareness and buy-in from the public, political actors and institutions to support road planning that better accommodates landscape connectivity and wildlife mobility. Awareness across non-ecology disciplines is a challenge well reported on the subject of wildlife crossings, and it was expressed through this work with the CACE project that, despite numerous guidelines and resources available on road ecology and wildlife crossing and road design as identified above, uptake of the TRCA Crossing Guideline has been poor. Therefore, there needs to be more awareness and added perspective from more diverse professional disciplines to contribute to the understanding of barriers to planning for wildlife crossing structures in the GTHA.

The three road projects identified in the CACE project demonstrated the variation in context for wildlife crossing structures in York Region. It suggests that another challenge exists in the streamlining of planning process for wildlife crossings at the project level when each site specific crossing project can have different stakeholders (e.i. Local and regional municipal and provincial governments), different levels of policy and legislation applied to it (e.i. 
Endangered Species Act), different ecological profile and any other number of differentiating factors which may complicate attempts at collaborative planning.

\subsubsection{Opportunities}

The opportunities discussed here build upon the identified strengths discussed above. The From a project and regional level, the CACE project itself is an opportunity for streamlining landscape data collection to directly support and inform crossing design as early in the process as possible. In addition, it has opened the door to opportunities for partnership development between interested and willing partners across disciplines including academia and municipal government. This may create opportunity for more transdisciplinary collaboration in future with stronger presence of other actors including academia. This would contribute to developing more comprehensive studies of the barriers and solutions to wildlife mobility in the planning context through the inclusion of diverse professional perspectives. Further, continued action research, such as that provided through this study, which builds on and differentiates from existing public resources and guidelines such as the TRCA Crossing Guideline (through its focus on applied use of the resource) is expected to encourage better uptake of these documents and enhance the planning process of wildlife crossings.

\section{$\underline{3.4 \text { Prognosis }}$}

There are many courses of action that may encourage more transdisciplinary collaboration and/or enhance the planning of wildlife crossing infrastructure and wildlife mobility across landscapes. However, given the context, focus and limited scope of this study, this "Prognosis" phase proposes one such recommendation to be explored further in the "Prototype" and "Test" phases of the provided framework. It is recommended that the use of the CoLaboratory model be explored via in-situ testing to uncover further barriers and opportunities to enhancing the efficiency of the planning of wildlife crossing structures and landscape connectivity both at the project level and the broader systems level. This is recommended to contribute valuable feedback to previous phases of this conceptual framework and/or to feed into the following "Prototype" phase. Figure 16 illustrates the CoLaboratory process in the context of wildlife crossing infrastructure and situates this recommendation in the context of this study's framework. 


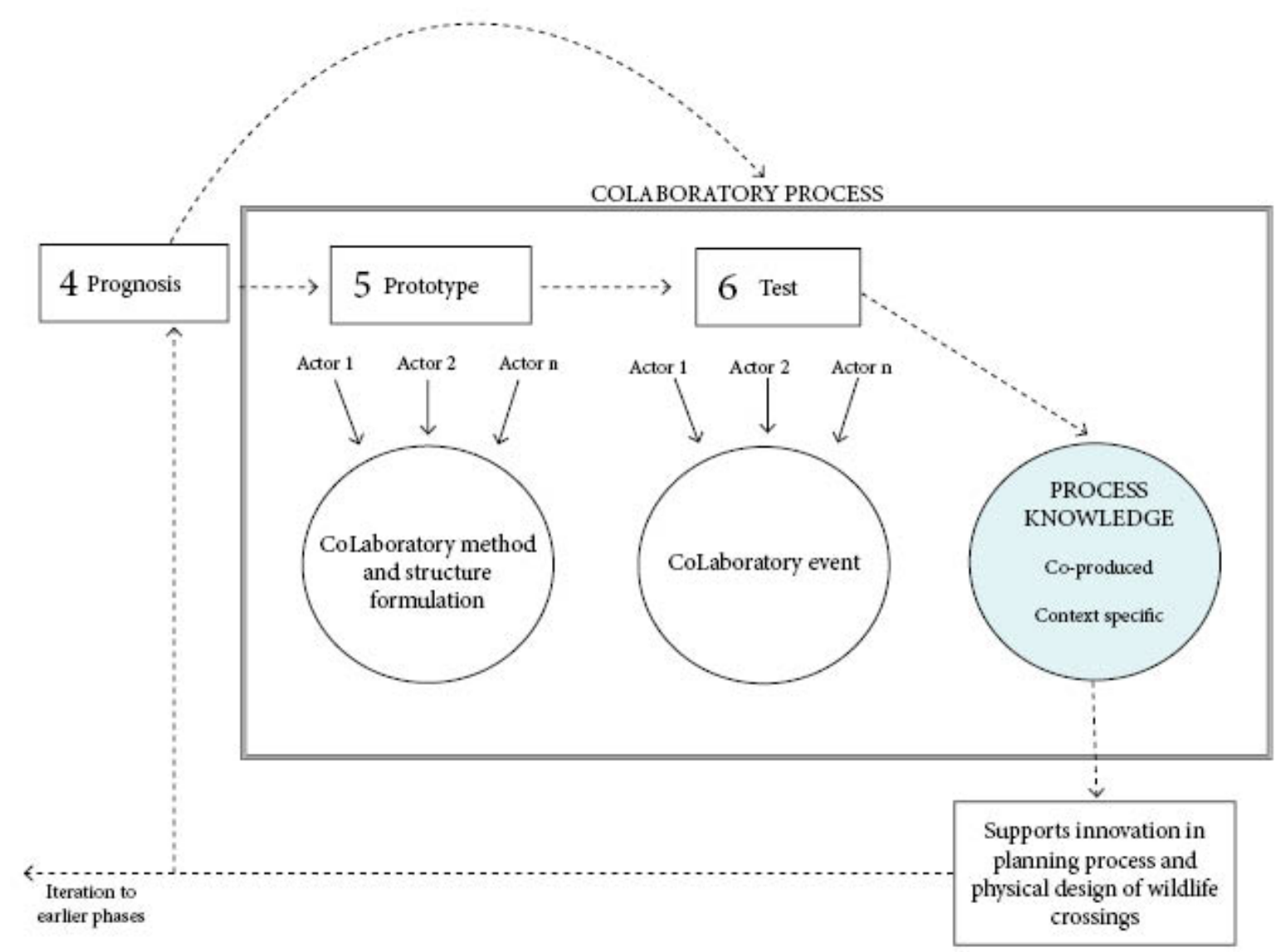

Figure 16. Illustration of CoLaboratory Process and its incorporation into the study framework (Adapted from Aird 2017).

As discussed earlier in this paper, the CoLaboratory model can be considered a design process which encourages transdisciplinary collaboration towards co-creating solutions to common problems and goals. This discussion will consider the merits of the CoLaboratory model in addressing the challenges identified in this study but will refrain from discussing best practices for the formatting of the CoLaboratory itself. This would be better suited for the Prototype phase where the format of the CoLaboratory can be the subject of further research and co-production with participating actors to ensure appropriate alignment with context, collective objectives and constraints. The work by Aird (2017) explores the CoLaboratory model in the format of the design charrette and the planning studio as well as the literature surrounding their success in process efficiency and is a good resource for future prototyping in the context of wildlife crossing infrastructure in this study.

The context, scale and communicative power of landscapes represents a conducive setting for the application of the CoLaboratory model and is supported through research and existing precedents (Tress et al. 2005; Opdam \& Nassauer 2008; Dramstad \& Fjellstad, 2011). As discussed earlier in this report landscape scale challenges are 
complex and require holistic approaches to address them. It is understandable then that the CoLaboratory model inherently applies these qualities through its iterative design, interdisciplinarity and collaborative problem solving characteristics.

The discussion on the stakeholder scan earlier in this report highlighted the roles and powers of different actors within relevant disciplines and agencies in planning for wildlife crossing structures. In partnership with the other components of analysis in this study, the inclusion of diverse professional perspectives in the co-creation of knowledge as well as technical and non-technical solutions to addressing the action-gap is essential. This study in itself is largely grounded in the perspective of the CA in the planning of wildlife crossings in the GTHA as the professional expertise was collected through working with the TRCA. The CoLaboratory model is inherently transdisciplinary and in this context would demand the participation of actors from a CA and ecology perspective, but also those from municipal, political and engineering perspective.

The CoLaboratory model removes practitioners from their professional silos in which routine patterns of thought and practice are ingrained and positions them in a new and professional diverse setting in which innovation, mutual learning and collective problem solving are the primary objectives. This has the effect of lessening disciplinary and jurisdictional divides in the spirit of innovation and collaboration and creates a setting more conducive to analyzing and strategizing solutions to complex problems (Aird 2017; Austin et al. 2010; Lister et al. 2015; Agger \& Sørensen 2018). This can be seen in the example provided earlier in this report regarding the ARC design competition. This example, although focused on physical design solutions, had a positive effect in gathering diverse perspectives together in creating an innovative outcome and fostering mutual learning. This applies to products of non-technical and procedural nature as well (Long 2012; Geissdoerfer et al. 2016).

Creating a separate space for collaboration may also be a solution to overcoming contention and conflict surrounding road projects, as it may distance itself from the details of a contentious ongoing project and instead focus on collectively achieving larger shared objectives through a spirit of innovation and collaboration (Austin et al. 2010; Godeman 2008). This is not to say that a CoLaboratory focused on a specific project(s) should be avoided, a certain level of real application is important to ensure that generated solutions are practical. However, it may be useful to be considerate of context and the ability to attract diverse participants into the process of collaboration when considering the format of a CoLaboratory. Regardless of outcome (whether it be physical design or process design), there is value in the CoLaboratory model in generating a greater awareness and shared understanding, existing process and barriers, 
stakeholder roles and power dynamics and identifying willing and interested partners for continued collaboration (Austin et al. 2010; Tress et al. 2005; Kleinsmann \& Valkenburg 2008).

In a logistical sense, the CoLaboratory model typically gets participants together in the same physical space, requires face-to-face communication and perhaps in interactions in which they would otherwise not find themselves. This form of face-to-face communication enables more effective collaboration and communication amongst practitioners in different disciplines and may work to remove barriers from virtual and written communication challenges (Kleinsmann \& Valkenburg 2008). Further, the format of the CoLaboratory is a contained to a set timeline and organization of events which can be tailored to accommodate a specific context. In addition, this format supports the challenge identified in this study that proposed solutions should be compatible with existing processes and work to enhance them. The CoLaboratory could operate outside of the framework of the EA and land use planning process and work to enhance these processes instead of countering them through creating greater awareness and communication between participants to apply in their practice.

The CoLaboratory model therefore has meaningful potential in enhancing the efficiency of planning for landscape connectivity and wildlife mobility at the broader regional scale but at the project-level as well. In the specific context of York Region and the TRCA, the CoLaboratory model is recommended as it has the potential to leverage and build upon the existing strengths identified in this study. As demonstrated in this report, the TRCA already has landscape data and interested municipal and academic partners to initiate dialogue surrounding the potential of a CoLaboratory. These interested partners, including those within the TRCA, have demonstrated proactiveness and willingness to collaborate through the development of the aforementioned landscape data and the CACE project. Further, York Region represents an ideal setting in another sense. As a region home to a considerable amount of natural heritage features as well as considerable projected population growth and development, the region could position itself as a leader in integrated planning and leading with the landscape for the rest of the GTHA.

\subsection{Moving Forward - Prototype and Test}

Although these phases are not assessed specifically or explicitly in this study, it is important to acknowledge the role of these future phases in the context of case study and for the continuation of this work. For the case study, the "Prototype" and "Test” phases largely account for the "solution space” of the conceptual framework. This study has largely worked to set the stage for the "problem space” regarding the planning for wildlife crossing planning in York Region. Exploring the "solution space" within the context of the case study will yield more actionable insight 
into how to streamline the CACE project and its lessons to broader landscape planning in York Region. Moving forward, a CoLaboratory exercise is being planned in collaboration between the TRCA and the EDL to develop tangible design solutions for wildlife crossing structures and will embody these two phases. 


\section{CONCLUDING DISCUSSION}

This study was a response to the well reported policy and action gap between the science of road and landscape ecology and the practice of land use and road infrastructure planning. This has limited the potential of wildlife crossing infrastructure to be used as a mainstream mitigation tool to facilitate wildlife mobility and enhance ecosystem resilience. As discussed in this report, the challenge of planning for and implementing wildlife crossing infrastructure fits within the broader challenge of landscape connectivity and sustainability which has been characterized as a wicked problem. As such, the application of transdisciplinary and design thinking approaches to solving this challenge were explored in this study in a number of ways. It was researched and discussed as a topic of analysis in itself and was demonstrated through practice through the study's development, methodology and conceptual framework. The conceptual framework was an effective strategy for integrating a diversity and variety of concepts spanning road ecology, planning, design thinking and transdisciplinarity and for deriving valuable insight in assessing the case study.

The transdisciplinary and design thinking perspective was successful in framing the challenge relating to landscape connectivity in a way that is more grounded in existing practice and local context. In addition, it was successful in shifting the perception of the problem away from ecological issues to that of the decision making, political, and planning processes that create and are meant to solve these problems. In other words, it reframes the issues that arise from habitat fragmentation from roads as symptomatic of the underlying lack of integrating planning. This perspective makes planning for connectivity and wildlife mobility the responsibility of all relevant disciplines and agencies and as such requires the dismantling of disciplinary and jurisdictional divides in order to rise to the challenge.

This, of course, raises more complex questions and suggests solutions that are equally challenging and complex but its hits the heart of the issue. The CoLaboratory model was proposed in this study as a tool to foster greater cross-disciplinary and inter-agency understanding and collaboration in order to collectively identify and interpret barriers and co-create new solutions to achieve a more efficient and effective process for planning of wildlife crossing infrastructure. While this study does not provide a complete picture of the challenges facing transdisciplinary collaboration in this context in the GTHA, it does contribute action-oriented research to inform and support further studies. It applies a local, context-specific lens needed to effectively address the action gap in the study area and 
provides a precedent for the use of design thinking in transdisciplinary action research in landscape planning, road ecology and other intersecting fields of inquiry. 


\section{REFERENCES}

Agger, A., \& Sørensen, E. (2018). Managing collaborative innovation in public bureaucracies. Planning Theory, 17(1), 53-73.

Ahern, J. (2013;2012;). Urban landscape sustainability and resilience: The promise and challenges of integrating ecology with urban planning and design. Landscape Ecology, 28(6), 1203-1212.

Ahern, J., Cilliers, S., \& Niemelä, J. (2014). The concept of ecosystem services in adaptive urban planning and design: A framework for supporting innovation. Landscape and Urban Planning, 125(Complete), 254-259.

Aird, B. (2017). CoLaboratory Methodology \& Context. Unpublished manuscript, School of Urban and Regional Planning, Ryerson University, Toronto, Canada.

ARC Solutions. (2014). Design parameters report. Workshop for wildlife-crossing infrastructure. Bozeman, MT: Western Transportation Institute, Montana State University.

Argyris, C., Schön, D.A. (1991). Participatory Action Research and Action Science Compared: A Commentary. In

Whyte, W.F. (Ed.), Participatory Action Research. (pp. 85-95). SAGE Publications.

Austin, J.M., Slesar, C., Hammond, F.M.(2010). Strategic Wildlife Conservation and Transportation Planning: The Vermont Experience. In J.P. Beckmann, A. P. Clevenger, M. Huijser \& Jodi A. Hilty (Eds.), Safe Passages: Highways, Wildlife, and Habitat Connectivity. (pp. 239-256). Island Press.

Beckmann J.P. \& Hilty, J. A. (2010). Connecting Wildlife Populations in Fractured Landscapes. In J.P. Beckmann, A. P. Clevenger, M. Huijser \& Jodi A. Hilty (Eds.), Safe Passages: Highways, Wildlife, and Habitat Connectivity. (pp. 3-16). Island Press.

Benítez-López, A., Alkemade, R., \& Verweij, P. A. (2010). The impacts of roads and other infrastructure on mammal and bird populations: A meta-analysis. Biological Conservation, 143(6), 1307-1316.

Botequilha Leitão, A., \& Ahern, J. (2002). Applying landscape ecological concepts and metrics in sustainable landscape planning. Landscape and Urban Planning, 59(2), 65-93.

Carl, S. (2018, February 12). In Defense of Biodiversity: Why Protecting Species from Extinction Matters. Yale Environment 360. Retrieved from https://e360.yale.edu/features/in-defense-of-biodiversity-why-protecting-speciesfrom-extinction-matters 
Carruthers, C. \& Lister (2011). Mapping Our Heritage: Towards an Integrated Planning Framework for CulturalNatural Heritage in Prince Edward County. Technical Report Prepared for the Prince Edward-Lennox Addington Community Futures Program.

CEAA (Canadian Environmental Assessment Agency). (2014). Basics of Environmental Assessment. Retrieved from the Government of Canada website: https://www.ceaa-acee.gc.ca/default.asp?lang=en\&n=B053F859-1

Coffin, A. W. (2007). From roadkill to road ecology: A review of the ecological effects of roads. Journal of Transport Geography, 15(5), 396-406.

Cross, N. (1982). Designerly ways of knowing. Design Studies, 3(4), 221-227.

Dale, A., \& Hill, S. B. (2001). At the edge: Sustainable development in the 21st century. UBC Press.

De Santo, R. S., \& Smith, D. G. (1993). An introduction to issues of habitat fragmentation relative to transportation corridors with special reference to high-speed rail (HSR). Environmental Management, 17(1), 111-114.

Dramstad, W. E., \& Fjellstad, W. J. (2011). Landscapes: Bridging the gaps between science, policy and people. Landscape and Urban Planning, 100(4), 330-332.

Eldin, M. \& Levin, M. (1991). Cogenerative Learning: Bringing Participation into Action Research. In Whyte, W.F. (Ed.), Participatory Action Research. (pp. 127-142). SAGE Publications.

Elton, K. (2015) Wildlife \& Roadways: Incorporating Wildlife Management Strategies Into Road Infrastructure in Southern Ontario (master's thesis). University of Waterloo, Waterloo, ON.

Fagan, W., \& Calabrese, J. (2006). Quantifying connectivity: Balancing metric performance with data requirements. In K. Crooks \& M. Sanjayan (Eds.), Connectivity Conservation (Conservation Biology, pp. 297-317). Cambridge: Cambridge University Press.

Fahrig, L., \& Rytwinski, T. (2009). Effects of roads on animal abundance: An empirical review and synthesis. Ecology and Society, 14(1), 21.

Fenech, A., Taylor, B., Whitelaw, G., \& Hansell, R. (2005). Changes in the major roads of southern Ontario, Canada 1935-1995: Implications for protected areas. In A. Fenech, D. MacIver, \& H. Auld (Eds.), Integrated Mapping Assessment (pp. 93-113). Toronto, Ontario: Meteorological Service of Canada, Environment Canada. 
Forman R.T.T., Sperling D., Bissonette J.A., Clevenger A.P., Cutshall C.D, Dale V.H, Fahrig L., France R., Goldman C.R, Heanue K., Jones J.A, Swanson F.J, Turrentine T., Winter T.C. (2003). Road Ecology: Science and Solutions. Island Press, Washington.

Forman, R. T. T., \& Alexander, L. E. (1998). Roads and their major ecological effects. Annual Review of Ecology and Systematics, 29(1), 207-231.

Friedrichs, J., \& Lüdtke, H. (1975). Participant observation: Theory and practice. Saxon House.

Geissdoerfer, M., Bocken, N. M. P., \& Hultink, E. J. (2016). Design thinking to enhance the sustainable business modelling process - A workshop based on a value mapping process. Journal of Cleaner Production, 135(Complete), 1218-1232.

Government of Ontario. (2015). Preparing environmental assessments. Retrieved from the Government of Ontario website: https://www.ontario.ca/environment-and-energy/preparing-environmental-assessments

Habermas, J. (1984). The theory of communicative action. Beacon Press.

Hardy A., Wombach D. (2010). An Eco-Logical Approach to Transportation Project Delivery in Montana in Fractured Landscapes. In J.P. Beckmann, A. P. Clevenger, M. Huijser \& Jodi A. Hilty (Ed.), Safe Passages: Highways, Wildlife, and Habitat Connectivity. (pp. 3-16). Island Press.

Head, B. W. (2016). Working with wicked problems in socio-ecological systems: More awareness, greater acceptance, and better adaptation. Landscape and Urban Planning, 154(Complete), 1-3.

Healey, P. (1997). Collaborative planning: Shaping places in fragmented societies. UBC Press.

Holling, C.S. \& Goldberg, M.A. (2014). Ecology and Planning. In Reed, C. \& Lister, N. (Eds.), Projective Ecologies. (pp.106-125). Harvard University Graduate School of Design. (reprint 1971).

Huijser, M. P., Duffield, J. W., Clevenger, A. P., Ament, R. J., \& McGowen, P. T. (2009). Cost-benefit analyses of mitigation measures aimed at reducing collisions with large ungulates in the united states and canada: A decision support tool. Ecology and Society, 14(2), 15.

Johansson-Sköldberg, U., Woodilla, J., \& Çetinkaya, M. (2013). Design thinking: Past, present and possible futures. Creativity and Innovation Management, 22(2), 121-146. 
Jorgensen, D. L. (1989). Participant observation: A methodology for human studies. SAGE.

Karlson, M., Mörtberg, U., Balfors, B., Miljöbedömning och -förvaltning, KTH, Skolan för arkitektur och samhällsbyggnad (ABE), \& Mark- och vattenteknik (flyttat 20130630). (2014). Road ecology in environmental impact assessment. Environmental Impact Assessment Review, 48, 10-19.

Kleinsmann, M., \& Valkenburg, R. (2008). Barriers and enablers for creating shared understanding in co-design projects. Design Studies, 29(4), 369-386.

Kociolek, A.V., Ament, R.J., Callahan, A.R., Clevenger, A.P., (2014). Wildlife crossings: the new norm for transportation planning. ITE Journal (Institute of Transportation Engineers) 85, no. 4 (2015): 45-47.

Leavy, P. (2011). Essentials of transdisciplinary research: Using problem-centered methodologies. Left Coast Press.

Lindberg, T., Meinel, C. \& Wagner, R. (2011). Design Thinking: A Fruitful Concept for IT Development? In Meinel, C., Leifer, L., \& Plattner, H. (Eds.). Design thinking: understand - improve - apply. Springer Berlin Heidelberg.

Long, J. G. (2012). State of the studio: Revisiting the potential of studio pedagogy in U.S.-based planning programs. Journal of Planning Education and Research, 32(4), 431-448.

McCarthy, D., \& Canadian Environmental Assessment Agency. (2010). Exploring strategic environmental assessment in the context of a rapidly urbanizing municipality: A case study of the regional municipality of york, ontario, canada, a synthesis report for the canadian environmental assessment agency Canadian Environmental Assessment Agency.

Meinel, C., Leifer, L., \& Plattner, H. (2011). Design thinking: Understand - improve - apply. Springer Berlin Heidelberg.

Metrolinx. (2008). The Big Move: Transforming Transportation in the Greater Toronto and Hamilton Area. Retrieved from the Metrolinx website:

http://www.metrolinx.com/thebigmove/en/introduction/1_3_GTHA_challenges.aspx

MFO (Ontario Ministry of Finance). (2017). Ontario Population Projections Update, 2016-2041. Retrieved from the Ministry of Finance website: https://www.fin.gov.on.ca/en/economy/demographics/projections/ 
Moilanen, A., \& Nieminen, M. (2002). Simple connectivity measures in spatial ecology. Ecology, 83(4), 1131.

MNR (Ministry of Natural Resources). (2008). Strategy for preventing and managing human-wildlife conflicts in Ontario. Toronto, Canada: Queen’s Printer for Ontario.

MMAH (Ministry of Municipal Affairs \& Housing). (2014). Provincial Policy Statement. Toronto, ON.

Musacchio, L. R. (2011). The grand challenge to operationalize landscape sustainability and the design-in-science paradigm. Landscape Ecology, 26(1), 1-5.

Nassauer, J. I., \& Opdam, P. F. M. (2008). Design in science: Extending the landscape ecology paradigm. Landscape Ecology, 23(6), 633-644.

Newman, W. L. (2000). Social Research Methods: Qualitative and Quantitative Approaches. Boston: Allyn \& Bacon.

Niemelä, J. (1999). Ecology and urban planning. Biodiversity and Conservation, 8(1), 119-131.

OBC (Ontario Biodiversity Council). (2011). Ontario’s Biodiversity Strategy, 2011: Renewing Our Commitment to Protecting What Sustains Us. Ontario Biodiversity Council, Peterborough, ON.

Cowie, A. (2011). Biodiversity in Ontario's Greenbelt. Ontario Nature, Toronto, ON. Retrieved from: https://www.ontarionature.org/discover/resources/PDFs/reports/REPORT-GB_Habitat-Dec2011.pdf

OREG (Ontario Road Ecology Group). (2010). A Guide to Road Ecology in Ontario. Scarborough, ON.: Ontario Road Ecology Group.

Opdam, P., Foppen, R., \& Vos, C. (2001). Bridging the gap between ecology and spatial planning in landscape ecology. Landscape Ecology, 16(8), 767-779.

Petersen, B., Montambault, J., \& Koopman, M. (2014). The potential for double-loop learning to enable landscape conservation efforts. Environmental Management, 54(4), 782-794.

Sawaya, M.A., Clevenger, A.P., \& Kalinowski, S.T. (2013). Demographic connectivity for ursid populations at wildlife crossing structures in Banff National Park. Conservation Biology, 27(4), 721-730. 
Sawaya, M. A., Kalinowski, S. T., \& Clevenger, A. P. (2014). Genetic connectivity for two bear species at wildlife crossing structures in Banff National Park. Proceedings. Biological Sciences/the Royal Society, 281(1780), 20131705-20131705.

Stoney, C., \& Winstanley, D. (2001). Stakeholding: Confusion or utopia? mapping the conceptual terrain. Journal of Management Studies, 38(5), 603-626.

Swaffield, S., \& Deming, M. E. (2011). Research strategies in landscape architecture: Mapping the terrain. Journal of Landscape Architecture, 6(1), 34-45.

Razzouk, R., \& Shute, V. (2012). What is design thinking and why is it important? Review of Educational Research, 82(3), 330-348.

Taylor, P. D., Fahrig, L., Henein, K., \& Merriam, G. (1993). Connectivity is a vital element of landscape structure. Oikos, 68(3), 571-573.

Thering, S., \& Chanse, V. (2011). The scholarship of transdisciplinary action research: Toward a new paradigm for the planning and design professions. Landscape Journal: Design, Planning, and Management of the Land, 30(1), 618.

Tischendorf, L., \& Fahrig, L. (2000). How should we measure landscape connectivity? Landscape Ecology, 15(7), 633-641.

van der Ree, R., Jaeger, J.A.G, van der Grift, E.A. \& Clevenger, A. P. (2011). Effects of roads and traffic on wildlife populations and landscape function: Road ecology is moving toward larger scales. Ecology and Society, 16(1), 1.

Vanlaar, W.G.M, Gunson, K.E., Brown, S.W. \& Robertson R.D. (2012). Wildlife-Vehicle Collisions in Canada: A Review of the Literature and a Compendium of Existing Data Sources. Traffic Injury Research Foundation, Ottawa, ON.

Tress, G., Tress, B., \& Fry, G. (2005). Clarifying integrative research concepts in landscape ecology. Landscape Ecology, 20(4), 479-493.

Walker, D. H. T., Bourne, L. M., \& Shelley, A. (2008). Influence, stakeholder mapping and visualization. Construction Management and Economics, 26(6), 645-658. 
Wang, Z., Tan, P. Y., Zhang, T., \& Nassauer, J. I. (2014). Perspectives on narrowing the action gap between landscape science and metropolitan governance: Practice in the US and china. Landscape and Urban Planning, 125, 329-334.

Westley, F. \& McGowan, K. (2014). Design Thinking, Wicked Problems, Messy Plans. In Reed, C. \& Lister, N. (Eds.), Projective Ecologies. (pp. 290-311). Harvard University Graduate School of Design.

Whyte, W.F., Greenwood D.J., Lazes, P. (1991). Through Practice to Science in Social Research In In Whyte, W.F. (Ed.), Participatory Action Research. (pp. 30). SAGE Publications.

Wu, J. \& Hobbs, R. (2002). Key issues and research priorities in landscape ecology: an idiosyncratic synthesis. Landscape Ecol. 17: 355-365.

Wu, C., Isaksson, K., Antonson, H., KTH, Samhällsplanering och miljö, Urbana och regionala studier, \& Skolan för arkitektur och samhällsbyggnad (ABE). (2017). The struggle to achieve holistic landscape planning: Lessons from planning the E6 road route through tanum world heritage site, sweden. Land use Policy, 67, 167.

Xiang, W. (2013). Working with wicked problems in socio-ecological systems: Awareness, acceptance, and adaptation. Landscape and Urban Planning, 110, 1-4.

York Region. (2017). York Region Growth and Development Review 2016. Retrieved from York Region website: http://www.york.ca/wps/wcm/connect/yorkpublic/def64590-6ce9-438c-a20f-

60cd1f76502c/17052_gdr2016AccessibleVersion.pdf?MOD=AJPERES

Yuan, J. (2014). Road ecology protocols: procedures for incorporating road mitigation measures into Toronto's infrastructure operations (master's thesis). York University, Toronto, ON. 